ORNL/TM-2002/199

\title{
PROCESSING COST ANALYSIS FOR BIOMASS FEEDSTOCKS
}

Phillip C. Badger

OAK RIDGE NATIONAL LABORATORY 


\section{DOCUMENT AVAILABILITY}

Reports produced after January 1, 1996, are generally available free via the U.S. Department of Energy (DOE) Information Bridge.

Web site http://www.osti.gov/bridge

Reports produced before January 1, 1996, may be purchased by members of the public from the following source.

National Technical Information Service

5285 Port Royal Road

Springfield, VA 22161

Telephone 703-605-6000 (1-800-553-6847)

TDD 703-487-4639

Fax 703-605-6900

E-mail info@ntis.fedworld.gov

Web site http://www.ntis.gov/support/ordernowabout.htm

Reports are available to DOE employees, DOE contractors, Energy Technology Data Exchange (ETDE) representatives, and International Nuclear Information System (INIS) representatives from the following source.

Office of Scientific and Technical Information

P.O. Box 62

Oak Ridge, TN 37831

Telephone 865-576-8401

Fax 865-576-5728

E-mail reports@adonis.osti.gov

Web site http://www.osti.gov/contact.html

This report was prepared as an account of work sponsored by an agency of the United States Government. Neither the United States Government nor any agency thereof, nor any of their employees, makes any warranty, express or implied, or assumes any legal liability or responsibility for the accuracy, completeness, or usefulness of any information, apparatus, product, or process disclosed, or represents that its use would not infringe privately owned rights. Reference herein to any specific commercial product, process, or service by trade name, trademark, manufacturer, or otherwise, does not necessarily constitute or imply its endorsement, recommendation, or favoring by the United States Government or any agency thereof. The views and opinions of authors expressed herein do not necessarily state or reflect those of the United States Government or any agency thereof. 


\title{
PROCESSING COST ANALYSIS FOR BIOMASS FEEDSTOCKS
}

\section{Phillip C. Badger}

General Bioenergy, Inc.

Florence, Alabama

Date Published: October 2002

\author{
Prepared for \\ U.S. Department of Energy \\ Office of Energy Efficiency and Renewable Energy \\ Biomass Program \\ Budget Activity Number EB 2404000
}

Prepared by

OAK RIDGE NATIONAL LABORATORY

Oak Ridge, Tennessee 37831

managed by

UT-BATTELLE, LLC

for the

U.S. DEPARTMENT OF ENERGY

under contract DE-AC05-00OR22725 


\section{CONTENTS}

\section{Page}

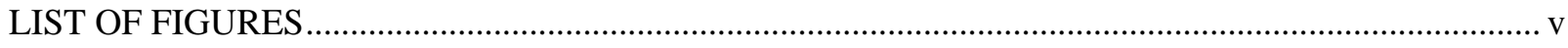

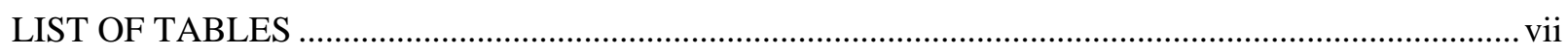

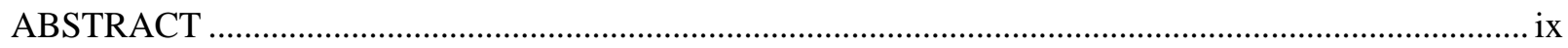

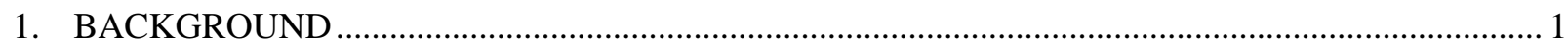

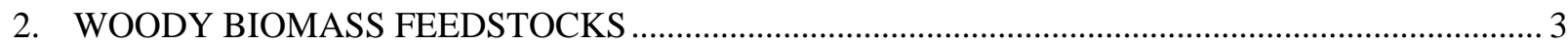

3. DIRECT COMBUSTION, GASIFICATION, AND SMB TECHNOLOGIES ................................. 11

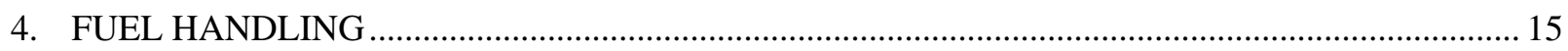

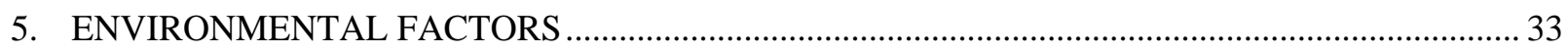

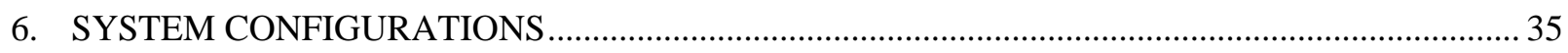

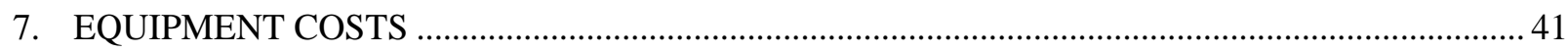

8. RECOMMENDATIONS FOR DECREASING ON-SITE CAPITAL AND O\&M COSTS

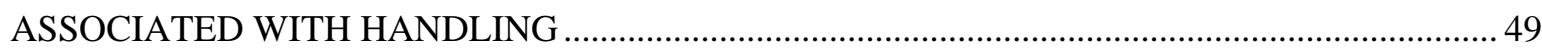

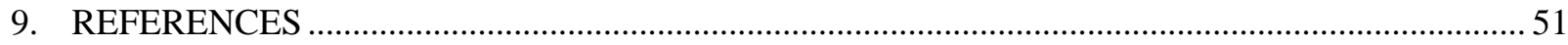




\section{LIST OF FIGURES}

Figure $\quad$ Page

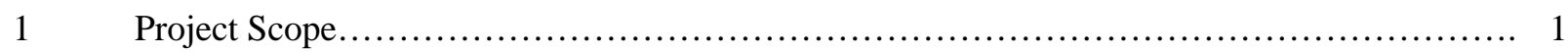

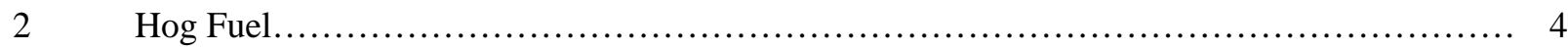

3 A Mixture of Chips, Shavings, and Hog Fuel...................................... 5

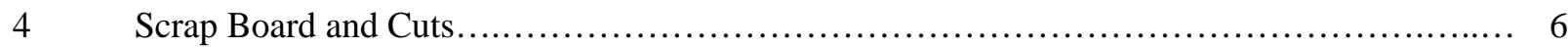

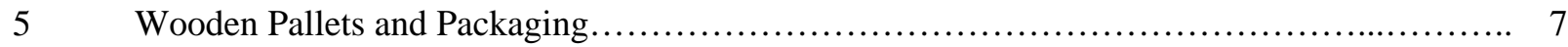

6 A "Mono-Load" of Commercial Tree Trimmings Before Hogging ........................... 8

7 Generic Modern-Day Plant Gate to Conversion Device Fuel Handling System for a LargeScale Biopower Plant.............................................................. 15

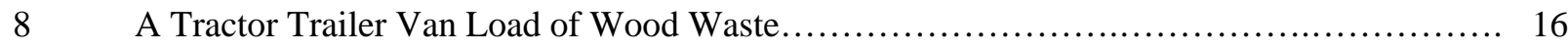

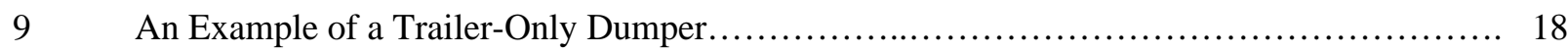

10 Another Example of a Trailer-Only Dumper........................................ 18

11 An Example of an Oscillating Screen............................................ 20

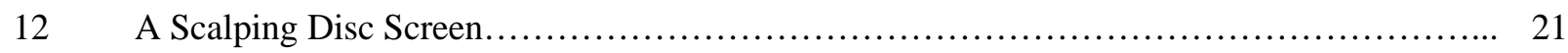

13 A Bunker Storage System with Roof Retracted to Allow Fuel to be Dumped into

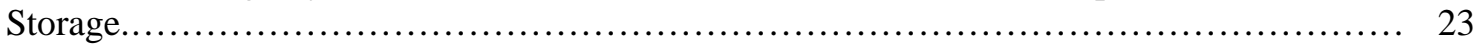

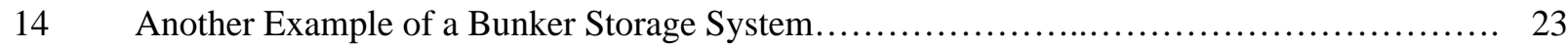

15 An Enclosed Metal Bin with a Traversing Auger Unloader............................. 24

16 An Example of a Live Bottom Truck Bed Used as a Permanently Stationed Fuel Bin.......... 24

17 An Open Shed Wood Storage System with a Trailer-Only Dumper in the Foreground........ 25

18 An Example of Silo, Open-Shed, and Open-Pile Wood Storage Systems Used

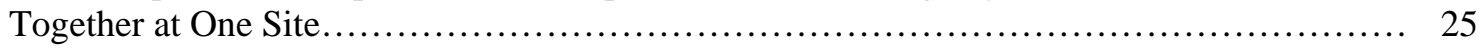

19 An Example of a Radial Stacker Loader with the Storage Currently Empty................... 26

20 A Very Large Open-Pile with Bulldozer Managing the Pile................................ 26

21 The Concept of the Moving Hole Feeder............................................... 27 


\section{LIST OF FIGURES (Cont'd)}

Figure

22 A Front-End Loader, Rotary Dryer, and Metal Silo Storage System...................... 30

23 A Rotary Drum Drying System Showing Ducting and Particulate Capture System............ 31

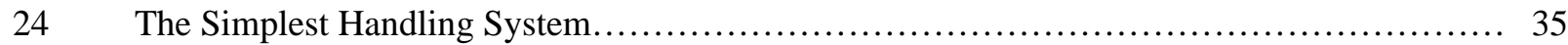

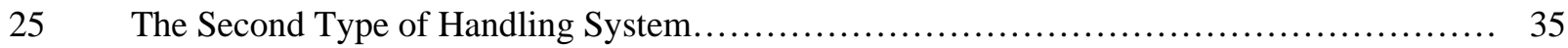

26 A Front-End Loader, Storage Pile in Building, and Feed Hopper with Live Bottom........... 36

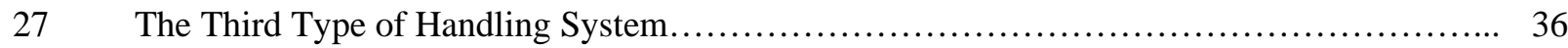

28 The Fourth Handling System with Scales Added..................................... 36

$29 \quad$ Handling System for Intermediate Scale Systems and Dirty Fuels....................... 37

$30 \quad$ Handling System for the 54.5 MW Wood Chip Fired Biopower Plant in

Burlington, Vermont............................................................ 38

31 Handling System for the 80 MW Wood Waste Fired Biopower Plant at Hurt,

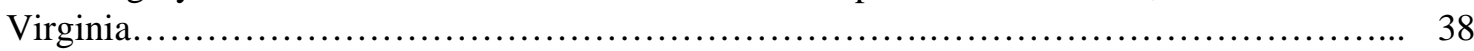

32 Separate Scales with Bar Code Scanners are Used to Weigh Incoming and

Outgoing Trucks at the 90 MW Plant at Hurt, Virginia.................................. 39

33 Calculation of Truncated Pyramid Dimensions for a Given Volume with $45^{\circ}$ Side

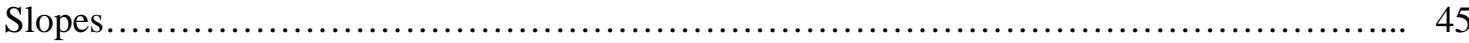




\section{LIST OF TABLES}

Table

Page

1 Summary of Wood Fuel Specifications by Burner Type (GLRBEP, 1986 with others

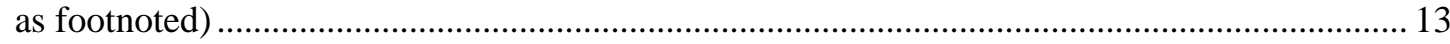

2 Unit Weights of Various Wood Fuels at Various Moisture Contents ...................................... 22

3 Advantages and Disadvantages of Wood Fuel Conveying Systems (GLRBEP, 1986;

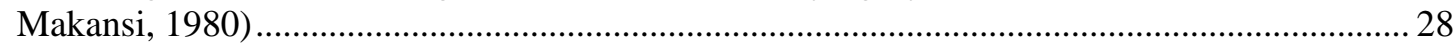

4 Requirements for Various-Sized Wood Fired Power Plants with 14 Days of Reserve

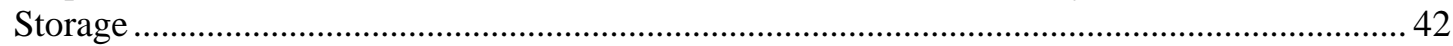

5 Requirements for Various-Sized Wood Fired Power Plants with 28 Days of Reserve

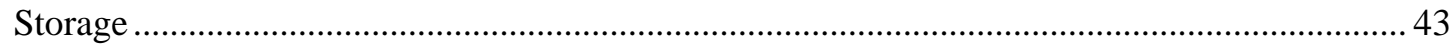

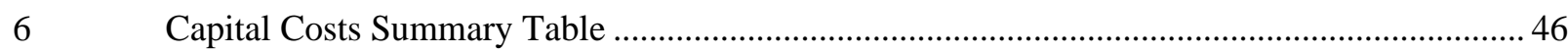

7 Cost Estimates for Conveyors and Hoppers (conveyor length dimensions are pulley

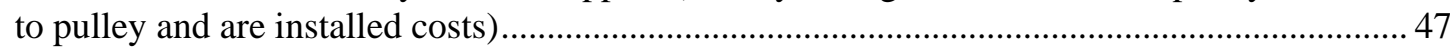

$8 \quad$ Installed Costs for Rotary Drum Dryers Capable of Drying From 50 to 12\% Moisture

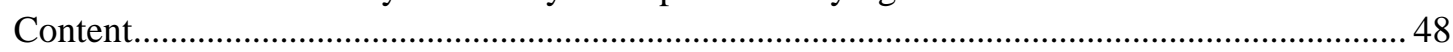

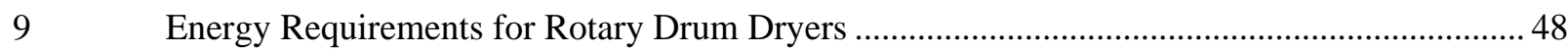




\begin{abstract}
The receiving, handling, storing, and processing of woody biomass feedstocks is an overlooked component of biopower systems. The purpose of this study was twofold: (1) to identify and characterize all the receiving, handling, storing, and processing steps required to make woody biomass feedstocks suitable for use in direct combustion and gasification applications, including small modular biopower (SMB) systems, and (2) to estimate the capital and operating costs at each step. Since biopower applications can be varied, a number of conversion systems and feedstocks required evaluation.

In addition to limiting this study to woody biomass feedstocks, the boundaries of this study were from the power plant gate to the feedstock entry point into the conversion device. Although some power plants are sited at a source of wood waste fuel, it was assumed for this study that all wood waste would be brought to the power plant site. This study was also confined to the following three feedstocks (1) forest residues, (2) industrial mill residues, and (3) urban wood residues. Additionally, the study was confined to grate, suspension, and fluidized bed direct combustion systems; gasification systems; and SMB conversion systems. Since scale can play an important role in types of equipment, operational requirements, and capital and operational costs, this study examined these factors for the following direct combustion and gasification system size ranges: 50, 20, 5, and $1 \mathrm{MW}_{\mathrm{e}}$.
\end{abstract}

The scope of the study also included:

- Specific operational issues associated with specific feedstocks (e.g., bark and problems with bridging);

- Opportunities for reducing handling, storage, and processing costs;

- How environmental restrictions can affect handling and processing costs (e.g., noise, commingling of treated wood or non-wood materials, emissions, and runoff); and

- Feedstock quality issues and/or requirements (e.g., moisture, particle size, presence of non-wood materials).

The study found that over the years the industry has shown a good deal of ingenuity and, as a result, has developed several cost effective methods of processing and handling wood. SMB systems usually cannot afford to perform much onsite processing and therefore usually purchase fuels processed to specification. Owners of larger systems try to minimize onsite processing to minimize processing costs. Whole truck dumpers are expensive, but allow for faster and easier unloading, which reduces labor costs and charges by the haulers.

Storage costs are a major factor in overall costs, thus the amount of fuel reserve is an important consideration. Silos and bins are relatively expensive compared to open piles used for larger facilities, but may be required depending on space available, wood characteristics, and amount of wood to be stored. For larger systems, a front-end loader has a lot of flexibility in use and is an essential piece of equipment for moving material.

Few opportunities appear to exist for improving the cost effectiveness of these systems. 


\section{BACKGROUND}

The receiving, handling, storing, and processing of woody biomass feedstocks is an overlooked component of biopower systems. The purpose of this study was twofold: (1) to identify and characterize all the receiving, handling, storing, and processing steps required to make woody biomass feedstocks suitable for use in direct combustion and gasification applications, including small modular biopower (SMB) systems, and (2) to estimate the capital and operating costs at each step. Since biopower applications can be varied, a number of conversion systems and feedstocks required evaluation.

In addition to limiting this study to woody biomass feedstocks, the boundaries of this study were from the power plant gate to the feedstock entry point into the conversion device. Although some power plants are sited at a source of wood waste fuel, it was assumed for this study that all wood waste would be brought to the power plant site. This study was also confined to the following three feedstocks (1) forest residues, (2) industrial mill residues, and (3) urban wood residues. Additionally, the study was confined to grate, suspension, and fluidized bed direct combustion systems; gasification systems; and SMB conversion systems. Since scale can play an important role in types of equipment, operational requirements, and capital and operational costs, this study examined these factors for the following direct combustion and gasification system size ranges: 50, 20, 5, and $1 \mathrm{MW}_{\mathrm{e}}$.

The scope of the study also included:

- Specific operational issues associated with specific feedstocks (e.g., bark and problems with bridging);

- Opportunities for reducing handling, storage, and processing costs;

- How environmental restrictions can affect handling and processing costs (e.g., noise, commingling of treated wood or non-wood materials, emissions, and runoff); and

- Feedstock quality issues and/or requirements (e.g., moisture, particle size, presence of nonwood materials).

Figure 1 summarizes the scope of this project. Feedstocks come with a variety of physical and chemical characteristics. Conversion devices require certain feedstock characteristics in order to process them. The fuel preparation steps in between must change the characteristics inherent in the feedstocks into the characteristics needed for the conversion device, and must do so cost-effectively while meeting acceptable environmental standards. Furthermore, in order in ensure feedstock reserves against supply disruptions, some storage of feedstocks is required at some point between the plant gate and conversion device.

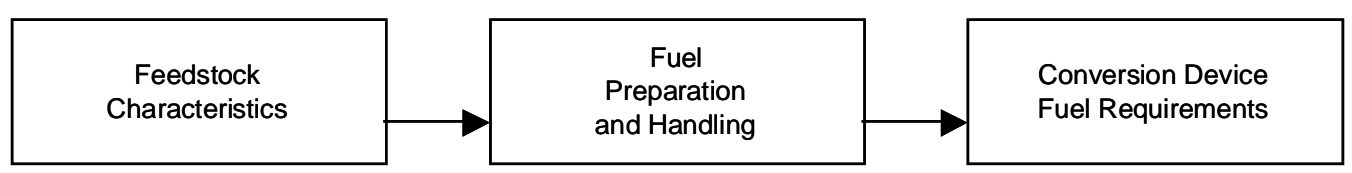

Figure 1. Project Scope.

This study will thus begin with the following sections: (1) woody biomass feedstocks, (2) conversion devices, and (3) the processing steps for converting feedstocks into the proper characteristics for the appropriate conversion device, followed by process system configurations and costs. 


\section{WOODY BIOMASS FEEDSTOCKS}

This study was confined to the following three feedstocks (1) forest residues, (2) industrial mill residues, and (3) urban wood residues, which represent typical woody feedstocks for biopower systems. These definitions are general in nature and do not reflect the wide variations that can occur due to types of wood present, moisture content, particle size and shape, presence of non-wood materials, and other factors that can affect the design of handling systems. These factors can vary so widely that it is often said that the only consistent property of wood is its inconsistency.

Moisture content is an important wood fuel characteristic and can be measured on a green or dry basis. The green basis, which will be used in this study, is defined as the weight of water divided by the total weight, expressed as a percent. The dry basis is defined as the weight of water divided by the weight of dry matter, expressed as a percent.

The maximum moisture content permissible for wood to be used as a fuel is in the range of 65 to 68 percent. Above this moisture content, the energy required to evaporate the moisture is greater than the energy in the dry matter of wood, and combustion cannot be sustained without a supply of external energy.

For all systems, excessive fuel moisture can cause corrosion and blockages of the fuel handling and feed system, and a reduction in combustion efficiency (FBT, 1994). Wood contains acids, and with sufficient moisture, can be quite corrosive.

Forest Residues. Forest residues, as defined here, include low-value materials resulting from harvesting, thinning, and land-clearing operations for replanting from commercial logging and silvicultural operations. Wood waste harvested during commercial logging and silvicultural operations may include tops, limbs, bark, and whole trees. The whole trees may result from thinning, unmerchantable timber, or land clearing for replanting. Sometimes referred to as "virgin wood," this resource typically consists of wood, needles, leaves, and bark. The moisture content ranges from 40 to 60 percent, with higher moisture contents in actively growing plants and lower levels in dormant plants.

Typically, commercial pulp and timber is harvested in the field with a feller-buncher. This device is a harvester that severs the trees at their base and aggregates them into "bunches," which can then be skidded to a landing site with a skidder. The term skidder, by definition, refers to moving whole trees or logs of any length from the stump to a point near a road, with some portion of the skidded material being dragged along the ground (Bromley, 1976). This dragging procedure can allow the wood to pick up considerable soil particles in the bark, especially if the soil is wet.

Chipping is the primary method for harvesting forest residues for fuel. This process economically converts low quality wood like rough, rotten and salvageable trees, logging residues and excess growth into easily handled wood fuel. Wood chips are produced at the logging site by running unmerchantable timber through a disk chipper. The chips, which are nominally $25 \mathrm{~mm}$ by $25 \mathrm{~mm}$ by $6 \mathrm{~mm}$, are blown into a trailer for transport to the wood energy facility. Most leaves and dirt debris are removed from the chips by differences in particle density when the chips are blown into the transport trailer. 
Three types of chips are commonly produced: whole-tree chips produced primarily from unmerchantable timber, round-wood chips, and clean chips. Whole-tree chips are made in the forest by feeding the entire tree (trunks, limbs and branches) into the chipper. Round-wood chips are made from tree trunks, after the limbs and branches have been removed. Clean chips are made from tree trunks that have had their bark removed, and are usually sold for pulp markets (GLRBEP, 1986).

Clean chips, which are bark free, typically have ash contents of less than 0.05 percent. Since bark has a high ash content, which may be augmented by soil particles, whole-tree and round-wood chips have higher ash contents, typically in the range of approximately one percent (GLRBEP, 1986).

In the production of whole-tree chips, small branches and limbs are not reduced to sizes comparable with standard chips. Long slivers and splinters may become mixed with the wood chips and may jam material handling equipment. For this reason, it is recommended that whole-tree chips be screened before they are introduced into a wood energy handling system. Round-wood and clean chips are more consistent in size and may not require screening.

Industrial Mill Residues. Industrial mill residues from the processing of forest products are an important source of wood residues for energy. Since forestry processing residues from primary (e.g., pulp, paper, lumber) or secondary (e.g., furniture, composite boards, wooden handles) manufacturing operations have distinct differences, they are usually classified separately.

Primary mill residues, also called green mill residues, typically have a moisture content that is greater than 20 percent (GLRBEP, 1986), and are primarily produced by lumber mills and pulp and veneer plants. Examples of green mill residues include "hogged" bark that has been stripped from logs, chip rejects, sawdust, slabs, and end-cuts, which remain after green wood is sawn into boards. Depending on species, barks may be quite fibrous and stringy, requiring special handling considerations. "Hog fuel" (Figures 2 and 3) is a mixture of wood and bark, usually reduced to 50-75 $\mathrm{mm}$ chips and produced by a wood hog (grinder), from which it derives its name (FBT, 1994).

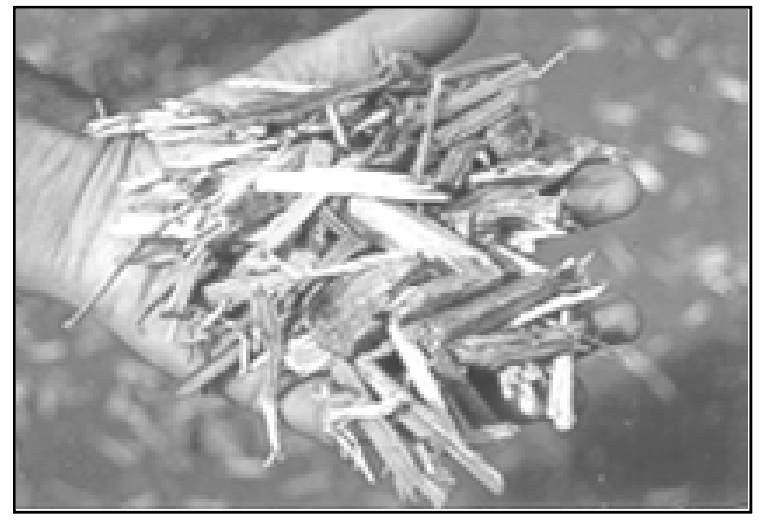

Figure 2. Hog Fuel. 


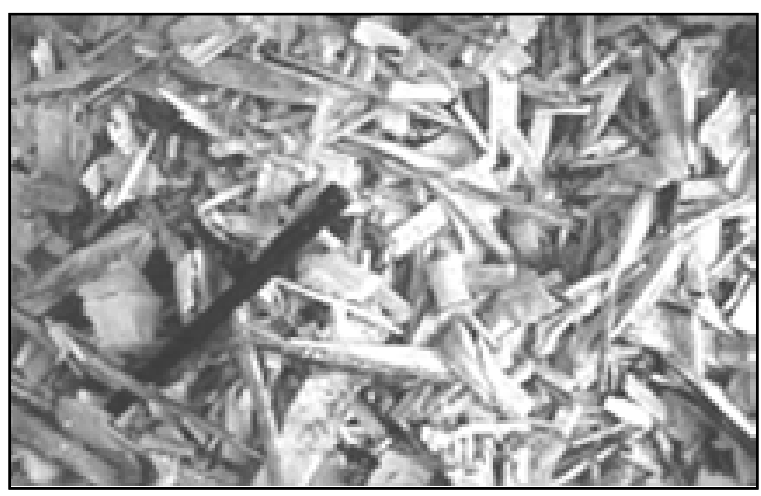

Figure 3. A Mixture of Chips, Shavings, and Hog Fuel.

Sawdust ash content may be as low as one-half percent, but bark has a relatively high ash content ranging from 3 percent to 4 percent (GLRBEP, 1986). The actual ash content of green mill residues depends on the manner in which the producer has handled the fuel. Typically, these residues are stored on the ground in large piles where spontaneous heating may occur. This heating results from a slow decomposition process, which not only reduces the energy content of the residues but also increases the ash content. In addition, if these residues are handled using front-end loaders, dirt and stones may be mixed with wood residues as the bottom of the residue pile is reached.

As with dry residues, uniformity of green mill residues is a key concern. Regularity of size, shape, moisture content, and availability is needed to fuel a wood energy system. Over-sized chunks of wood fuel may pose a problem both in handling and combustion. It may be necessary to reduce the fuel in size so that it can pass through the material handling system. A hog that shreds the oversized material at the point of pick-up or at the user site can accomplish this.

Secondary mill residues, also called dry mill residues, are the by-products of the wood products industry that utilize kiln-dried material to manufacture consumer and industrial goods. They are generally characterized by their relatively low moisture content, cleanliness, freedom from bark, and relatively high energy value.

Secondary mill residues may be in the form of sawdust, trimmings, shavings, flour, flawed dimension lumber, end cuts, chip rejects, sander dust, and other forms, all with varying physical and chemical characteristics (Figure 4). Residues from furniture, appliance, and cabinet manufacturing may also have surface coatings in the form of paint, varnish, or plastic-based laminates, as well as containing glues and adhesives, which may generate emissions during processing or require special handling. Residues from the manufacturing of poles, posts, and veneers are usually in the form of long slivers, making their handling difficult. Dimension lumber and end cuts can be in the form of large particles or chunks, requiring special handling considerations. Sander dust contains fine particles of sand, which can cause slagging and fouling in combustion and gasification units, and excessive wear on handling equipment. 


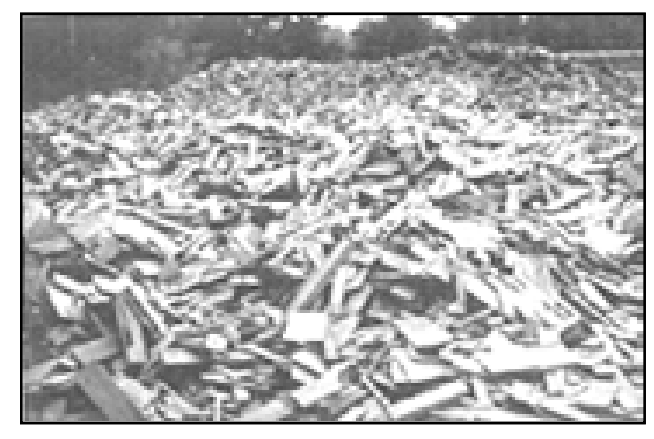

Figure 4. Scrap Board and Cuts.

Dry mill residues have a low moisture content, often less than 10 percent. As a rule of thumb, any wood that has to be glued in a manufacturing process must have moisture contents in the range of 5-6 percent. The lower moisture content gives dry mill residues a higher energy content than green residues. The ash content of dry residues is low and is typically measured at less than 0.5 percent on a dry weight basis (GLRBEP, 1986).

The major disadvantage of dry mill residue is the need for indoor storage. While green wood wastes may be stored outdoors in large piles, dry wood waste requires covered storage away from damp surfaces.

Urban Wood Residues. Industry groups or regulatory agencies have not specifically defined the term "urban wood residues. " However, it is widely used as a collective reference for wood waste present in municipal and commercial solid waste (Donovan, 1994). Urban wood residues can include construction and demolition (C\&D) wastes, wooden pallets, packaging materials, furniture and appliance cabinets, yard and tree trimmings, land clearing residues, and other forms of waste that are primarily wood.

Wood is a common component of $\mathrm{C} \& \mathrm{D}$ debris produced during the construction, renovation, and demolition of buildings, roads, and other structures. Wood content in C\&D debris can range from 15 to 85 percent by weight. The actual amount depends on the source and the methods of measurement (Donovan, 1994).

Wood from C\&D sources may contain both untreated and treated wood residues, as well as non-wood materials commingled with the wood. Treated wood can include creosote, pentachlorophenol (penta), or chromated copper arsenate (CCA) preservatives, insecticides, or fire retardants. These treatments are impregnated into the wood, making them physically inseparable. Other physically inseparable components may include glues, adhesives, binders such as in laminated beams, plywood, particleboard, or other composite materials; paints, stains, varnishes and other surface coatings including plastic laminates; and wood containing nails or attached to other non-wood materials such as shingles.

Physically separable commingled materials may include non-wood materials such as nails and other metals, plaster, concrete, asphalt, stone, shingles, tarpaper, and insulation. The average moisture content of C\&D wood is about 12 to 15 percent (Donovan, 1994). 
$C \& D$ wood wastes that find their way into energy markets are usually either source-separated or are taken to a $C \& D$ recycling center for separation and recovery of the various components, including wood. Although a variety of physical separation methods can be used to separate and recover the wood, usually a "positive pick" is used as a final step to insure that only untreated wood relatively free of commingled non-wood materials is obtained. A positive pick occurs when a human being visually inspects the wood, which is usually flowing by on a conveyor belt, and removes or picks only wood from the belt that has the desired properties.

To facilitate its handling and increase its value, this wood is processed through a hammermill or hog before delivery to the wood energy facility, thus offering an opportunity for the wood fuel purchaser to specify particle size and the degree of non-wood material that is acceptable.

Pallets and Wooden Packaging Materials. A large fraction of wood used in the United States is used to make wooden pallets (Figure 5). Only about 20 percent of these pallets are recycled, and the rest are discarded. In addition to containing nails and strapping from pallet repairs, pallets may contain preservatives or water repellants, and/or be contaminated with chemicals from spills while in service. However, most pallets are free of non-wood materials except for nails.

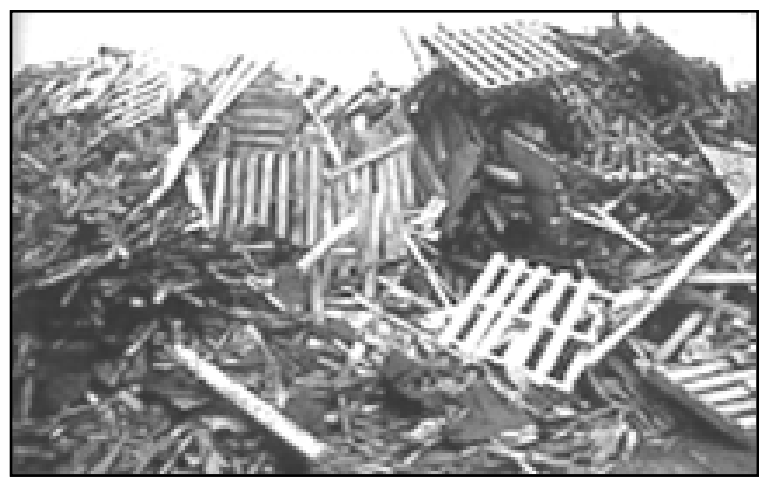

Figure 5. Wooden Pallets and Packaging.

Some pallets are designed for one-way service and are then discarded. These pallets may also be non-standard in dimensions or load-carrying capability. Similarly, wooden packaging materials are usually designed for one-way service.

In general, wooden pallets and packaging materials are constructed of hardwood and have a moisture content in the range of 12 to 15 percent, if stored indoors. For marketing as fuel, pallets and packaging materials are broken up in a hammermill and the metal removed with a strong magnet, resulting in a relatively high quality fuel. Processing by the residue generator allows the fuel purchaser to specify an acceptable particle size.

Commercial Tree trimmings. Commercial tree trimmers (arborculturists), clear utility right-of-ways and trim trees, producing a relatively clean, high-moisture content fuel that can range from 35 to 60 percent in moisture content, depending on the type of vegetation and time of year harvesting occurs. Typical commercial tree trimmers utilize drum chippers, which produce chips that are up to $25 \mathrm{~mm}$ by $6 \mathrm{~mm}$ by $75-100 \mathrm{~mm}$ long, and are blown directly from the chipper into a transport van. These 
chips can also contain significant amounts of leaves or needles; however, this method of handling generates a product that is usually free of soil, rocks, or metal containments. The presence of bark, leaves, and twigs increases the ash content slightly to 3 to 4 percent.

The big advantage of using commercial tree trimmings for fuel is their relatively consistent properties, and the fact that that they are not commingled with non-wood materials. If desired, they can be kept separate from other wastes and delivered in "mono-loads" to the biopower plant (Figure $6)$.

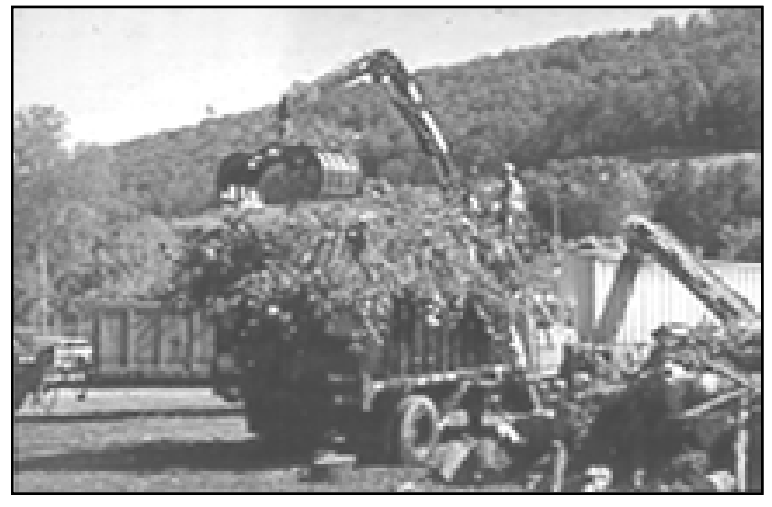

Figure 6. A "Mono-Load" of Commercial Tree Trimmings Before Hogging.

Urban land clearing. Clearing land for urban development can provide significant quantities of clean wood. In 2001, approximately 20 ha per day was cleared for urban development needs in the Atlanta metro area (Allen, 2001). The wood from urban land clearing is very similar to that described previously under forest residues, and is harvested in a similar manner. However, in addition to the forest resources discussed before, fuel from urban land clearing may contain wood from merchantable timber, as well as stumps. In general, the wood from the processing of stumps is not recommended for fuel purposes. Other wood from the land-clearing site can be kept separate, and can provide a relatively clean fuel stream with characteristics as described under forest residues.

Municipal solid waste (MSW). MSW contains all types of wood residues, including some fitting the categories just discussed, as well as some not specifically accounted for in the previous categories. Examples include wooden fencing, poles, cable reels, furniture, toys, posts, and appliance cabinets. Homeowners can also generate significant quantities of tree and bush trimmings; however, these resources are highly seasonal in nature and are almost always commingled with other non-wood and non-organic wastes, making their recovery and use difficult.

However, since landfilling costs are relatively high for a Subtitle D landfill required for MSW, and wood wastes can be placed in a lower cost inert landfill, most waste disposal authorities operate a separate inert landfill and provide incentives in the form of lower tipping fees to encourage the bringing of wood wastes to the inert landfills. Usually, only the wood that is brought to the landfill in the form of mono-loads of wood waste is recovered. This wood is typically allowed to air dry, and then processed through a tub or horizontal grinder to increase its density and value. 
MSW that is taken to a material recycling facility (MRF) will have the wood exit the facility as a separate stream. This wood is usually generated as a result of a positive pick, and thus can be relatively clean wood.

Major storms can result in significant increases in tree trimmings and tree pieces, including logs. Like normal commercial tree trimming operations, this wood is usually processed through drum chippers at its pickup site and blown directly into vans, resulting in a fairly clean, but high moisture content fuel. Alternatively, this wood is hauled to a central collection point and processed through a tub or horizontal grinder. This method of handling increases the probability of additional dirt and soil and other non-wood contaminants. 


\section{DIRECT COMBUSTION, GASIFICATION, AND SMB TECHNOLOGIES}

Feedstocks have certain inherent physical and chemical characteristics. The fuel preparation steps must change the characteristics inherent in the feedstocks into the characteristics needed for the conversion device, thus the feedstock requirements for the conversion device must be known. For purposes of this study, the conversion devices were limited to direct combustion and gasification applications, including small modular biomass (SMB) systems.

Direct combustion systems. Direct combustion systems commonly used for combustion of biomass fuels can be classified into pile, suspension, and fluidized bed combustion (FBC) systems. Pile combustion systems burn the wood fuel in either a heaped pile supported on a grate (used for smaller scale systems) which are horizontal or inclined, or in a thinly spread pile spread across a grate which may be traveling or stationary. These burners are sometimes referred to as Dutch oven or wet cell burners. Combustion air is provided both under the grate and above the fuel pile (Schmidt, 1991). The spreader-stokers fuel-feed and distribution systems used with "thin-pile" combustion units are generally quite reliable, with any problems most often traced to poor fuel distribution, which results from either oversize fuel or high moisture fuel particles (FBT, 1994).

Pile burners are noted for being relatively simple to design, low capital and operating costs, ability to take a fairly wide range of wood particles and moisture contents, and difficulty to control due to the large mass of burning fuel. Moisture contents up to 65 percent can be burned in pile burners. Minimum particle sizes depend on the grate openings while the maximum particle size depends on the fuel feed opening into the combustion chamber. In general, large chunks or stringy bark, or particles down to sawdust size may be used in these systems.

Underfeed stokers are another version of a pile burner. Underfeed stoker systems push fuel into the combustion chamber from beneath the burning pile. Usually an auger is used to push the fuel into the combustion chamber. Particles must be small enough to flow with the auger, and not too fine, stringy, or green to cause packing and blockage problems (FBT, 1994). The optimal particle size range is dependent on the auger size.

Suspension combustion systems are of two types, with both requiring fuel moisture contents less than 15 percent and uniform particle sizes with maximum dimensions less than $6 \mathrm{~mm}$ (Georgia Tech, 1984). Suspension burners include cyclonic burners and pneumatic spreader-stoker systems that burn fuel particles suspended in a turbulent air stream. Cyclonic burners consist of horizontal or vertical cylinders of cyclones with wood pneumatically injected along the tangent of the burn chamber. Centrifugal force suspends the particles while they are burned.

Air spreader-stoker systems typically consist of a rectangular firebox with a stationary or traveling grate at the bottom. The wood fuel is horizontally injected with air into the firebox above the grate so that most combustion occurs with the particles in suspension. Unburned particles complete their combustion on the grate. Although suspension burners are limited in their fuel handling capability, the fact that only a relatively small amount of fuel is burning at a given time allows these systems to be more responsive to changes in heat demands.

Fluidized bed combustion (FBC) systems burn the wood fuel on a high-temperature bed of finelydivided inert material, such as sand, that is agitated by air blown from beneath the bed. Solid fuel is introduced into the chamber via an airlock, where the fuel particles burn while suspended in the bed. This suspension allows combustion air to reach all sides of the particles throughout its combustion 
process, making for highly efficient combustion. FBC systems are particularly suited for burning fuels that contain high levels of ash, or consist of irregularly shaped particles, or have high moisture contents (Easterly and Lowenstein, 1986). Additionally, FBC systems have a very short residence time for their fuels (making these systems highly responsive to rapid changes in heat demand), high combustion efficiencies, the ability to handle a wide variety of fuels simultaneously, and reduced maintenance since the combustion chamber does not contain grates that must be cleaned, repaired, and replaced. These advantages are offset by the relative greater complexity of the systems and initial costs that are approximately 10 percent higher than grate systems (Georgia Tech, 1984)

The sizing of fuel is important. Small particles can pass through the unit and may not be caught by the cyclone for recycling back to the bed. Too large of particles can be too heavy to float in the fluidized bed, and cause problems (FBT, 1994).

Fuel and bed material are fed into the FBC using under-bed, in-bed, or over-bed feed systems. All systems need a pressure seal to force the fuel into the FBC and resist backpressure from the bed (FBT, 1994). A rotary airlock is often used for the pressure seal. This type of pressure seal requires fairly uniform particles of a size dependent of the size of the airlock. The fuel must also be dried to minimize plugging of the handling system.

Under-bed feed systems usually convey fuel pneumatically, and are more complex than the other types of feed systems. Sizing and drying the fuel are necessary to prevent handling system blockage. Under-feed systems are generally not used for biomass-fueled FBC systems.

In-bed feed systems are similar to the under-feed systems, particularly if the fuel is conveyed pneumatically, and are more complex than over-bed systems. In-bed systems are generally used for feeding high-moisture fuels, such as slurries, rather than the fuels of interest in this study (FBT, 1994).

Over-bed feed systems include conventional spreader feeders, air swept feeders/mills, and gravity feeders. These systems are less prone to blockages and are simpler to construct and maintain (FBT, 1994). Since the fuel entry point is above the pressurized bed, there is less pressure on the airlock, reducing the performance requirements of the airlock. For these reasons, over-bed feed systems are most commonly used to feed woody fuels into FBCs.

Gasification systems. Thermochemical gasification of biomass fuels involves the use of heat to decompose a feedstock under oxygen-limiting conditions. Gasification removes ash, including most alkali metals, and with gas-cleanup, removes particulates from the fuel stream. The gaseous form facilitates its use in a wider range of energy applications than solid fuels.

The most common types of gasifiers are upright and downdraft fixed bed systems and fluidized bed systems. Gasifiers can range in size from $18 \mathrm{MW}_{\mathrm{t}}$ and as large as $2400 \mathrm{MW}_{\mathrm{t}}$, with the maximum thermal output depending on gasifier design (Schmidt, 1991). Fixed bed gasifiers require fairly uniform particles of sufficient size to allow airflow through the bed. Standard $25 \mathrm{~mm}$ by $25 \mathrm{~mm}$ by 6 $\mathrm{mm}$ pulpwood chips have good physical dimensions for most gasifiers.

Feedstock moisture contents of up to 20 percent moisture content are acceptable for gasification systems (FBT, 1994), and moisture contents in the range of 15-25 percent actually increase gas production due to the conversion of the hydrogen in the water (Skov and Papworth, 1974). 
Fluidized bed gasifiers (FBG) work similarly to FBCs, except that oxygen in the gasification chamber is limited to minimize its combustion. Fuel requirements for FBGs are similar to FBCs. A major advantage of FBGs over fixed bed gasifiers is their ability to handle a wider variety of particle sizes and types of fuels at one time, and fuels with moisture contents up to 65 percent (FBT, 1994).

Small Modular Biomass (SMB) Systems. The term SMB as used here refers to a broad range of biopower systems of 1-5 $\mathrm{MW}_{\mathrm{e}}$ in size. Generally, the feedstock requirements are highly dependent on the conversion technology, and the conversion technology is usually designed for a particular feedstock.

\section{Table 1. Summary of Wood Fuel Specifications by Burner Type (GLRBEP, 1986 with others as footnoted)}

\begin{tabular}{|c|c|c|c|c|c|c|c|c|}
\hline & $\begin{array}{l}\text { Pile } \\
\text { burners } \\
\text { (wet } \\
\text { cells) }\end{array}$ & $\begin{array}{c}\text { Thin-pile spreader- } \\
\text { stoker }\end{array}$ & $\begin{array}{l}\text { Underfire } \\
\text { stokers }\end{array}$ & $\begin{array}{l}\text { Suspension, } \\
\text { cyclonic }\end{array}$ & $\begin{array}{l}\text { Suspension, air } \\
\text { spreader-stoker }\end{array}$ & FBCs & $\begin{array}{l}\text { Gasifiers, } \\
\text { fixed-bed }\end{array}$ & $\begin{array}{l}\text { Gasifiers, } \\
\text { FBG }\end{array}$ \\
\hline $\begin{array}{l}\text { Applicable } \\
\text { fuel type }\end{array}$ & $\begin{array}{l}\text { Virtually } \\
\text { any kind } \\
\text { except } \\
\text { wood } \\
\text { flour }\end{array}$ & $\begin{array}{l}\text { Sawdust, } \\
\text { non-stringy bark, } \\
\text { shavings, end cuts, } \\
\text { chips and chip } \\
\text { rejects, hog fuel }\end{array}$ & $\begin{array}{l}\text { Sawdust, } \\
\text { non-stringy } \\
\text { bark, } \\
\text { shavings, } \\
\text { chips, hog } \\
\text { fuel }\end{array}$ & $\begin{array}{l}\text { Sawdust, non- } \\
\text { stringy bark, } \\
\text { shavings, flour, } \\
\text { sander dust }\end{array}$ & $\begin{array}{l}\text { Sawdust, non- } \\
\text { stringy bark, } \\
\text { shavings, flour, } \\
\text { sander dust, } \\
\text { hog fuel }\end{array}$ & $\begin{array}{l}\text { Virtually } \\
\text { any kind } \\
\text { except } \\
\text { wood } \\
\text { flour and } \\
\text { stringy } \\
\text { materials }{ }^{2}\end{array}$ & $\begin{array}{l}\text { Chips, } \\
\text { hog fuel }\end{array}$ & $\begin{array}{l}\text { Virtually } \\
\text { any kind } \\
\text { except } \\
\text { wood flour } \\
\text { and stringy } \\
\text { materials }\end{array}$ \\
\hline Particle size & $\begin{array}{l}\text { Limited } \\
\text { by grate } \\
\text { size and } \\
\text { feed } \\
\text { opening }\end{array}$ & $6-50 \mathrm{~mm}$ & 6-38 $\mathrm{mm}$ & $6 \mathrm{~mm} \max$ & $6 \mathrm{~mm} \max$ & $\begin{array}{l}50 \mathrm{~mm} \\
\max ^{2}\end{array}$ & $6-100 \mathrm{~mm}$ & $6-50 \mathrm{~mm}^{2}$ \\
\hline $\begin{array}{l}\text { Moisture } \\
\text { content }\end{array}$ & $<65 \%$ & $10-50 \%$ & $10-30 \%$ & $<15 \%$ & $10 \%$ & $<60 \%{ }^{2}$ & $<20 \%$ & $15-65 \%^{2}$ \\
\hline
\end{tabular}

${ }^{1}$ Georgia Tech, 1984.

${ }^{2}$ FBT, 1994.

${ }^{3}$ Schmidt, 1991. 


\section{FUEL HANDLING}

Fuel handling includes all steps from truck weighing and unloading through fuel size reduction, screening, drying, storage, and feeding into the conversion device. Fuel feed system component sizes depend on boiler capacity requirements (Schmidt, 1991) and each component in the processing train must be sized to handle slightly more than the component ahead of it.

Feedstocks have certain inherent physical and chemical characteristics. The fuel preparation steps must change the characteristics inherent in the feedstocks into the characteristics needed for the conversion device, and must do so cost-effectively while meeting acceptable environmental standards. Based on these criteria, the fuel handling technologies and systems currently used in industrial wood firing systems have been developed over several decades. Figure 7 depicts a generic modern day plant gate-to-conversion device fuel handling system for a large-scale, wood-fueled direct combustion industrial application based on firing a steam boiler.

These generic systems include a method of weighing the incoming wood, a method for unloading the wood, a short-term storage unit, steps for size reduction and removal of non-wood materials, a longterm storage unit, a fuel metering device, and a device for feeding fuel into the combustion system. In between these various processing steps are various types of conveyance systems necessary for movement of the material from point to point (Badger, et al., 1987).

In some cases, a dryer is also included in the processing system. If a dryer is used, it is usually installed adjacent to the burner to remove moisture just before the fuel enters the combustion chamber.

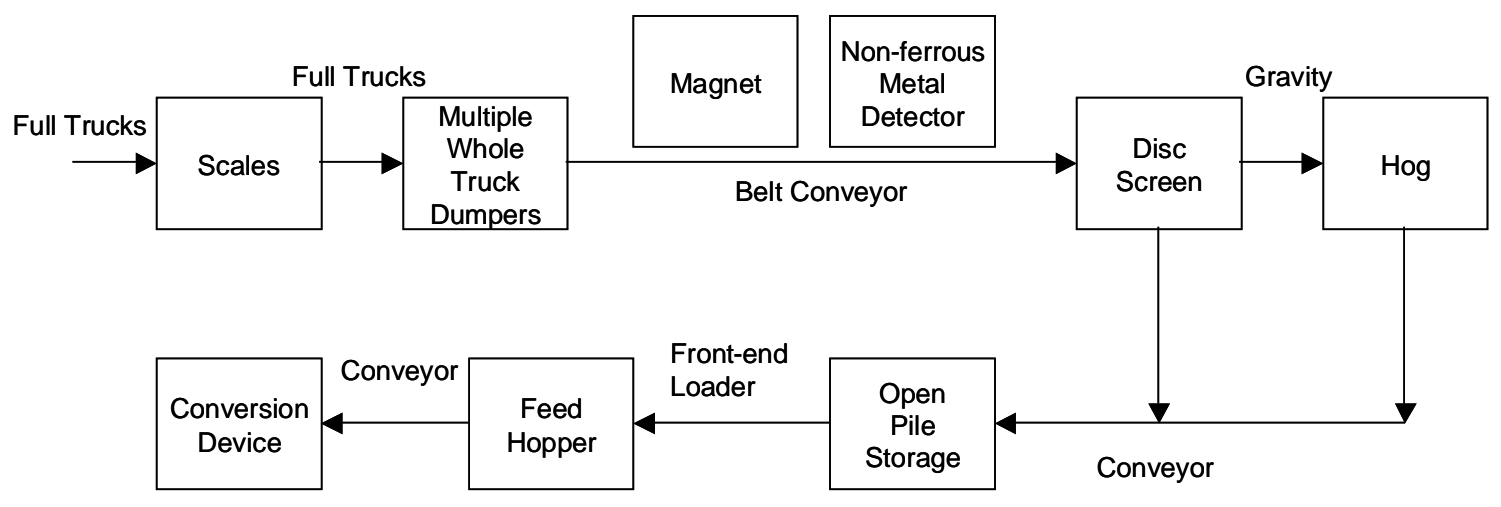

Figure 7. Generic Modern-Day Plant Gate to Conversion Device Fuel Handling System for a Large-Scale Biopower Plant.

Fuel handling and processing at the conversion plant can be a major portion of the system expense, with some estimates placing it at 20 to 40 percent of the total facility cost (Schmidt, 1991). Space requirements for a wood-fueled system are also quite different than for an oil- or natural gas-fired system. In planning for the detailed facility design, fuel handling must be viewed as part of the total system and contingencies planned for system failures. 
An extremely important part of the design of the fuel handling system is the ability to bypass most of the fuel preparation system in case of equipment breakdown. Thus, in an emergency, a front-end loader can be used to move raw fuel directly from the truck dump to the fuel-metering device, or entry point of the combustion unit, or between fuel processing points. The operator of the front-end loader also watches the fuel processing system for breakdowns or the presence of foreign materials in the fuel. Depending on the size of the operation and importance of the front-end loader for moving material, the front-end loader operator may also operate the truck dumper and scales (Badger, et al., 1987).

Fuel Blending. Various wood sources can have different physical and chemical characteristics, which can greatly influence its conversion to energy. Feeding of these materials with differing characteristics as slugs into the conversion device can cause rapid changes in operating conditions, and make control difficult. Even wood sources differing only in moisture content can cause significant variations in operating conditions and cause control problems.

Since wood is received from many different sources, and each source will have different characteristics, these fuel characteristic variations must be mitigated by fuel blending. Blending is accomplished several ways, starting with the normal handling and processing between the fuel delivery point and the conversion device, which tends to mix the fuel. Additionally, if fuel is stored in a linear or tent-shaped pile, material is spread along the length of the pile as it is conveyed into storage to create a layering effect. To further create blending, fuel is removed by scraping length-wise along the base of the pile.

Receiving and Unloading. With the exception of the wood residues generated in-house, virtually all fuel wood is delivered by truck to industrial wood users (Figure 8). A set of drive-on scales is used to determine how much wood is on the truck. Although mechanical or electronic scales may be used, generally maintenance costs are less for mechanical scales and therefore are more commonly used. Sometimes conveyor belt scales are used for determining weights, but these systems are less accurate, more time consuming, and more expensive to operate.

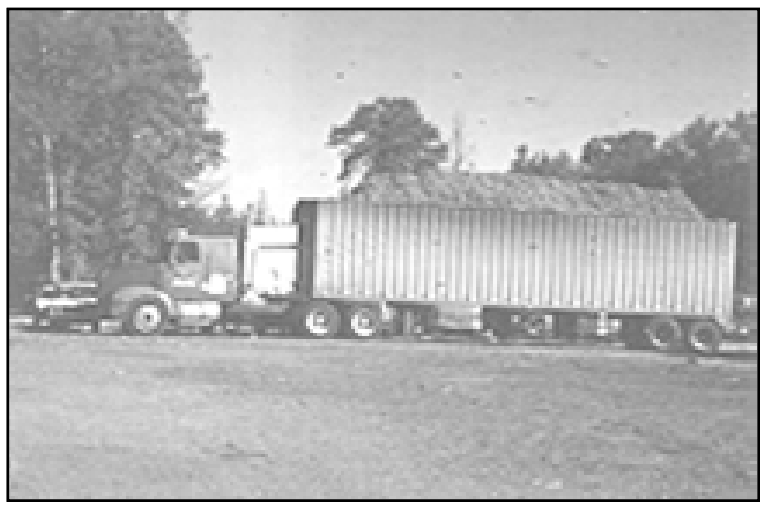

Figure 8. A Tractor Trailer Van Load of Wood Waste. 
Three types of trucks are commonly used for delivery of wood fuels: (1) dump trucks, (2) live-bottom (self-unloading) semitrailer vans, and (3) standard semitrailer vans, with the choice of truck dependent on the quantity purchased and the equipment available for unloading trucks. Dump trucks and live-bottom trucks have the advantage of being able to unload themselves directly onto storage piles. Standard semitrailer vans require truck dumpers. Smaller and less expensive dump systems only raise the trailer van for dumping, a process that requires decoupling the tractor and semitrailer and therefore consumes time. Larger dump units can tilt the whole truck and therefore can unload in a manner of minutes and in approximately one-half the time of a trailer-only dumper. Minimizing unloading times is important since the haulers can impose financial penalties for excessive unloading times.

The type of wood delivery system is determined, to a large extent, by the quantity of wood needed. Installations less than $8 \mathrm{GW}_{\mathrm{t}}$ may have wood delivered in dump trucks, live-bottom trailer vans, or regular trailer vans. Installations larger than $8 \mathrm{GW}_{\mathrm{t}}$ have wood delivered in regular semi-trailer vans and use dumpers capable of tilting the whole truck (GLRBEP, 1986).

Very small installations use small dump trucks or standard semi-trailer vans for wood delivery. Dump trucks are preferred for short-haul situations. Small dump trucks typically have a $12 \mathrm{~m}^{3}$ capacity and can be purchased used for $\$ 35,000$ to $\$ 55,000$, depending on condition and load rating (Thomas, 2002). For standard semi-trailer vans, a ramp or loading dock is used so that a small frontend loader can be driven into the van to unload it. Small front-end loaders cost in the range of $\$ 22,000$ to $\$ 26,000$ and can unload a semi-trailer van in less than an hour (Trulove, 2002).

Small-scale users also frequently utilize self-unloading semi-trailer vans. These trailers are equipped with a live floor that "walks" the load from the van and allows one person to unload a van within 10 minutes. Walking floors consist of a series of narrow, hydraulically operated floorboards that run lengthwise in the truck bed. To convey material, a series of adjacent boards will move toward the rear together and then retract one at a time to minimize pile contact area.

Trailers can range from 10-15 m in length, and carry between 20-30 tonnes of wood (GLRBEP, 1986). Some small-scale facilities use a self-unloading trailer as their fuel storage system, and simply activate the walking floor as fuel is needed. The advantage of self-unloading is offset by the selfunloading van cost, which is approximately $\$ 40,000$ (Jiles, 2002).

Intermediate-scale installations producing less than $8.5 \mathrm{GW}_{\mathrm{t}}$ of steam may also use a lighter duty hydraulic dumper for unloading fuel. These dumpers use a frame to tilt the semi-trailer van on its rear axle, a process that requires decoupling the tractor and semitrailer and therefore consumes time (Figures 9 and 10). However, this disadvantage is offset by the cost of the dumper (which includes a live bottom hopper), which is approximately \$234,000, installed (Farley, 2002).

Large-scale installations commonly use hydraulic dumpers that can lift and tilt the whole truck up to an angle of 75 degrees in a few minutes. These dumpers may require the trailer to be backed onto the unloader, or allow the truck to pull onto the dumper in a drive-through arrangement. For back-on systems, trucks back onto the lifting platform and are held in place by the frame of the lifting device. Dumping is completed in 3 to 5 minutes. A drive-through system has the truck drive across a grate. A frame then lifts to hold the trailer with its tractor in place during the dumping process. A complete hydraulic dumping station with a live-bottom receiving hopper will cost approximately $\$ 300,000$, installed (Farley, 2002, Brammer, 2002). 


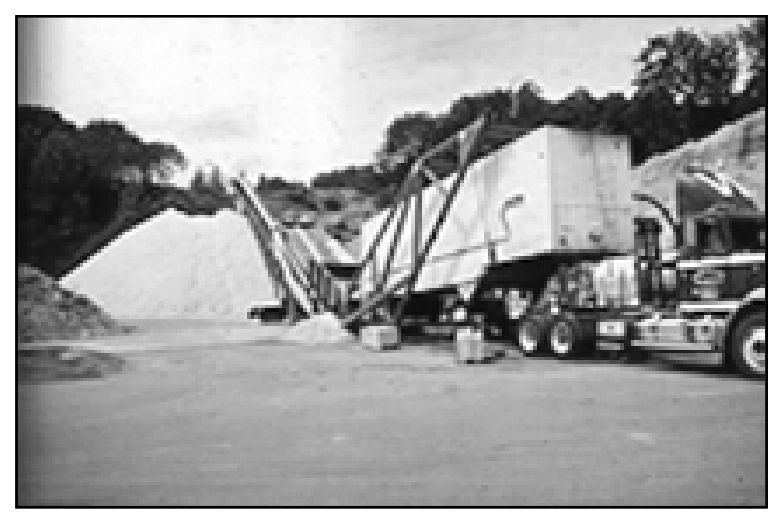

Figure 9. An Example of a Trailer-Only Dumper.

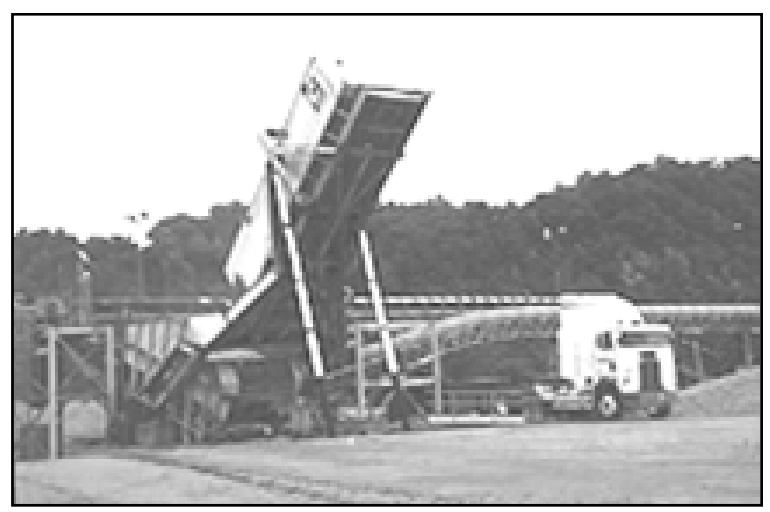

Figure 10. Another Example of a Trailer-Only Dumper.

Prolonged unloading times will result in imposition of increased costs by the hauler due to the lost revenue during unloading down time. Trucks also arrive randomly and, especially at large facilities, frequently arrive with other trucks. It is therefore customary to design wood fuel handling facilities so that they are able to accommodate half the daily volume of deliveries in one-third of the business day (GLRBEP, 1986; Makansi, 1980). Other remedies include providing 24-hour dumping accessibility and installation of multiple dumping stations.

Intermediate storage. Most installations provide some storage capability immediately after dumping, which acts as a surge "vessel" before further processing. For large and intermediate installations, the trailer van dumper has a built-in live-bottom storage hopper. The hopper size depends on the frequency of dumping and the size of the trucks performing the dumping. For small-scale installations, the storage is on a concrete pad and sometimes, depending on processing requirements, it is dumped directly onto the main storage pile. Intermediate storage also provides a quick means for visual load inspection, to look for oversize pieces or the presence of non-woody materials. 
Metal, stone, and dirt removal. The sooner that metals and other debris are removed from the fuel, the less likely they are to cause damage to fuel preparation equipment and the energy conversion device. Ferrous metals are removed with a magnet with various types in common use.

For removal of occasional ferrous tramp metal, a stationary magnet mounted above a conveyor is used. This magnet will usually have either a metal plate or a canvas "plate" between the magnet and the conveyor to facilitate removal of the metal. Self-cleaning magnets mount the magnet between the belts of a rapidly moving conveyor mounted above and perpendicular to the wood conveyor so that any metal that is attracted to the magnet is swept to the side by the magnet's conveyor. These magnets are used for applications with excessive loadings of ferrous metal pieces such as at wood recycling centers (e.g., recycling pallets), but generally not at wood-fired power plants since the wood fuel as delivered to a power plant is normally free of excessive metal (Gralnick, 2002).

A third method is to use a magnetized head pulley on the belt conveyor carrying the wood. The movement of the belt throws the wood forward while the metal sticks to the head pulley. The metal is carried around the pulley until the movement of the belt carries it away from the influence of the magnet, where it drops into a collection box below. Head pulley magnets are not feasible at pulley diameters below $300 \mathrm{~mm}$, as the small pulley diameters do not allow enough room to provide adequate magnet strength. A $300 \mathrm{~mm}$ diameter pulley can handle wood materials of 75-200 $\mathrm{mm}$ in depth. A $600 \mathrm{~mm}$ diameter pulley can handle material depths up to $150-200 \mathrm{~mm}$ in depth (Gralnick, 2002).

Non-ferrous metals cannot be removed with magnets; however, some plants use non-ferrous metal detectors to detect the presence of non-ferrous metals and stop the wood-carrying conveyor. The metal can then be visually identified by an operator and removed. The detectors operate on the eddycurrent principle and must be located on the conveyor so that the metal frame of the conveyor does not interfere with its operation. Sometimes a plastic conveyor bottom is installed in the section of conveyor where the detector is mounted to prevent interference from the metal frame.

Although various types of equipment are available for removal of stones and dirt from wood residues, very few wood-fired installations have equipment for removal of this material. Rather, the absence of stones and other debris is dictated by the contract with the fuel supplier, and failure to provide clean wood is cause for contract termination. A few plants use rotary trommel screens for this application.

Size reduction and screening. A "hog" is a device that is used to reduce the size of wood particles. Two types of hogs exist: knife types that chip the wood and hammermills that beat or grind the wood against a screen or spaced bars to reduce its size. Knife hogs have free-swinging knifes mounted on a horizontal shaft; however, cutting edges are sensitive to dirt and other debris, and therefore they are generally not used for fuel applications (Makansi, 1980).

Hammermills are typically horizontal shaft, swing-hammer types utilizing electric motors ranging from 75 to $220 \mathrm{~kW}$ that operate at high torque and high speed. They typically produce particle sizes in the range of 25-125 mm with a grinding rate of 20-55 tonnes/hr; however, they are limited to use with dry wood. Hammermills may employ different hammers and screens of different sizes and configurations, depending on wood input characteristics and final product desired (Donovan, 1994).

Considerations in purchasing a hog include the following (Makansi, 1980):

- The average and maximum amount of wood waste to be processed;

a The maximum incoming particle size;

- The required product particle size; and

- The nature of the wood waste that may require special design considerations. 
Most wood that is received is a mixture of particle sizes, with a high percentage of acceptable size. Passing all the wood through a hog increases the energy requirements and wear on the hog, and increases the amount of fine material. Therefore, screening the wood stream before the hog can remove particles of acceptable size requires the hog to process only oversized particles. For this reason, size reduction and screening are almost always linked.

Screens used include disc screens and oscillating or shaker deck screens (Figure 11). The latter is used less commonly and consists of either horizontal or inclined deck screens. The decks operate in a reciprocating or circular shaking motion and may be inclined 15 to 25 degrees. Decks may range in size from $0.6 \mathrm{~m}$ by $1.2 \mathrm{~m}$ to $2 \mathrm{~m}$ by $6 \mathrm{~m}$ and power requirements may range from $7.5-22 \mathrm{~kW}$. Multiple screen levels may be used to increase screening capability. The outputs from oscillating screens vary widely, based on the wood characteristics and the type and size of deck (Donovan, 1994). Oscillating screens are a high maintenance item and are not suitable for wet materials.

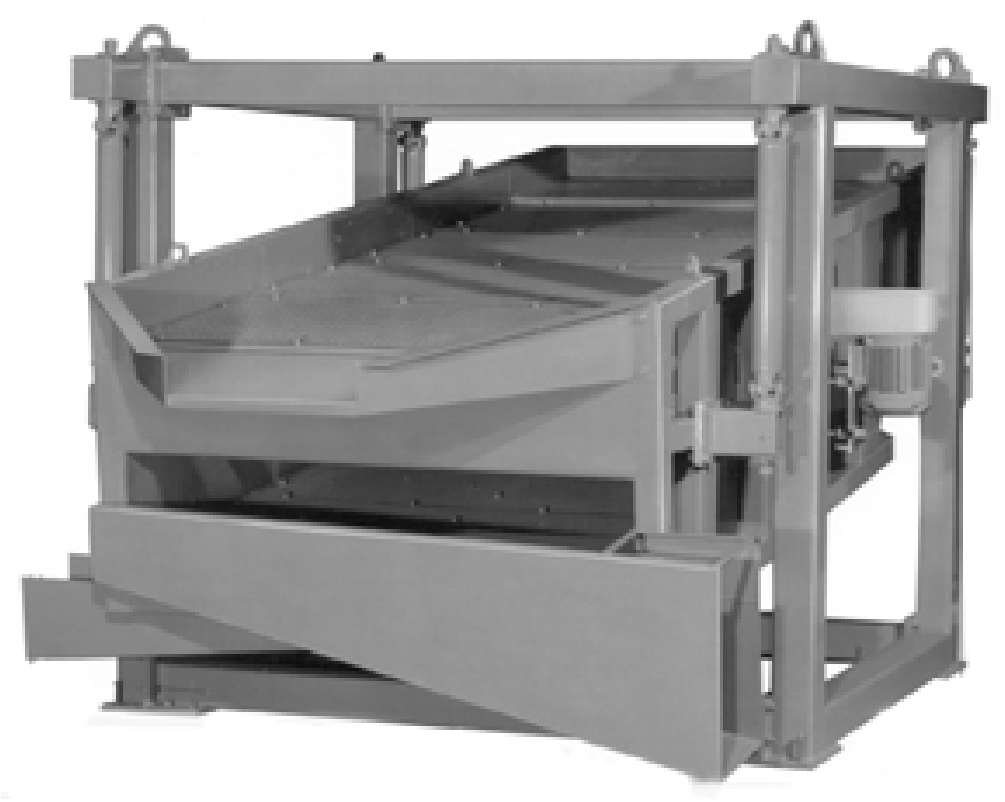

Figure 11. An Example of an Oscillating Screen.

The most common screen used for energy applications is the disk screen (Figure 12), which consists of a series of rapidly rotating disks (55-65 rpm is typical) mounted on several parallel horizontal rotating shafts (Makansi, 1980). Each shaft carries several equally spaced disks with the disks on adjacent shafts offset to allow them to interlace with each other. The disks are usually slightly starshaped or consist of fingers to help grab material and move it across the surface formed by the tops of the disks.

Oversize particles are rapidly carried across the top of the screen with the rest of the material dropping through the slots formed by the screen. Disk screens typically sort material between 25-150 $\mathrm{mm}$ in size (Donovan, 1994). Usually the disk screen is mounted before the hammermill or hog, to reduce the load on the hammermill or hog. 


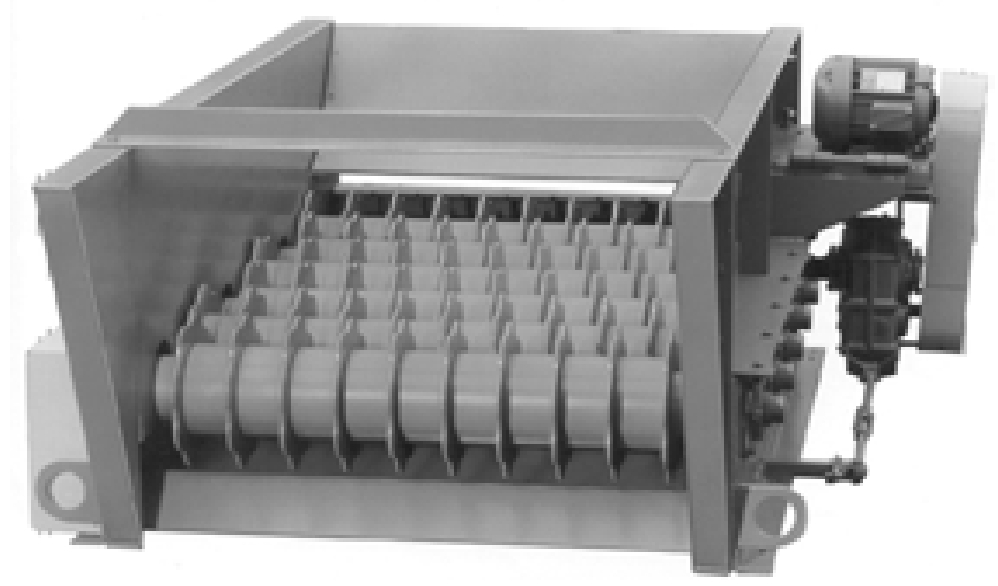

Figure 12. A Scalping Disc Screen.

A disk screen capable of processing 225 tonnes per hour can operate with a drive system of less than $15 \mathrm{~kW}$ (Makansi, 1980). Also, disk screens have the following advantages over other methods of screening (Makansi, 1980):

- Non-clogging and self-cleaning operation,

- High capacity, and

口 Ability to vary "screen" size.

For small-scale facilities, it is usually more economical to require the wood fuel provider to size and screen the wood before delivery. Selecting combustion equipment that can handle a wide range of particle sizes is also a partial solution for small-scale applications.

Primary storage. In designing a fuel storage facility, several factors must be considered (Schmidt, 1991):

- The storage area available and its location in reference to the boiler room,

- The properties of the wood fuel (i.e., moisture content, particle size, etc.),

- What additional fuel preparation facilities are required,

a The reliability of the wood fuel source,

a The weather conditions at the site, and

- Availability of additional personnel.

Moisture content affects the bulk densities and the heating values of the wood types, thereby directly affecting the volume of wood that must be stored. The volumetric fuel content affects

- The volumetric feed rate to the boiler,

- The volumetric storage requirements, and

a Number of delivery vehicles that must access the site. 


\section{Table 2. Unit Weights of Various Wood Fuels at Various}

Moisture Contents

\begin{tabular}{|c|c|c|c|c|}
\hline \multicolumn{5}{|c|}{ Weight per gravity-packed unit, } \\
$80 \mathrm{~kg} / \mathrm{m3}$ \\
\hline Moisture, \% & Hog fuel & Shavings & Bark & Sawdust \\
\hline 0 & 160 & 96 & 208 & 152 \\
\hline 10 & 178 & 107 & 231 & 168 \\
\hline 20 & 200 & 120 & 260 & 191 \\
\hline 30 & 227 & 136 & 296 & 216 \\
\hline 40 & 266 & 159 & 346 & 252 \\
\hline 50 & 320 & 192 & 416 & 304 \\
\hline
\end{tabular}

Source: Makansi, 1980.

Size of the conversion device, moisture content of the fuel, and storage reserve requirements all have major impacts on storage sizing requirements. Factors impacting storage reserve requirements are fuel source reliability, which can be impacted by weather, which can impact transportation or field harvesting conditions; and risk management requirements imposed by project investors and/or energy users. Since larger plants have a greater investment and therefore greater risk associated with them, their reserve requirements are disproportionally larger than smaller systems. Some designers of smaller systems that use mill residues and are located in mild climates only plan on two to three days storage - enough to get through weekend and holiday periods. The investors of the 90-MW (gross) wood waste fired facility in Hurt, Virginia, required a minimum of 30 days fuel reserve (Brammer, 2002). Due to its size, this facility must utilize all types of wood waste resources. One way to mitigate supply security is by using numerous suppliers that are located in different directions from the plant, using multiple access roads to the plant, and utilizing different wood waste suppliers.

Fuel storage facilities commonly consist of open, uncovered fuel piles; fuel piles partially covered by open sheds; and enclosed storage bins, hoppers, or silos. Small-scale installations are more likely to use enclosed hoppers or bins, due to the small quantities that they need and the increased protection that these structures provide. Hoppers, bins, silos, and bunkers are also used where storage space is minimal or where air pollution regulations require them.

Silos provide ease of fuel retrieval and require minimal space. The structures are generally vertical cylinders with the height 2 to 2.5 times the diameter. They may be constructed of metal, concrete stave and ring, or poured concrete. In general, silos with diameters from $6.5 \mathrm{~m}$ to $12 \mathrm{~m}$ are more cost effective using steel, and silos with diameters over $15 \mathrm{~m}$ or more are more cost effective using concrete (Kessler, 2002).

Silos are subject to bridging and "ratholing," unless carefully designed (Schmidt, 1991). Since most wood fuels have poor flow characteristics, silos are usually equipped with agitators such as chain flails or augers to prevent bridging. Wet or green fuels stored in silos are subject to freezing and adhering to the silo wall. One method to minimize freezing problems is to construct the silo so that its lower $6 \mathrm{~m}$ are within a heated building (GLRBEP, 1986).

Another covered storage system is the bunker, which can be used with both green and dry fuels. A bunker is a rectangular shaped concrete structure buried in the ground so that the top of the structure is at ground level. The top of the bunker may be covered or a shed constructed over it (Figures 13 and 14). Burial in the ground minimizes fuel-freezing problems and facilitates truck unloading directly into the bunker. A live-bottom is used to remove fuel (GLRBEP, 1986). 


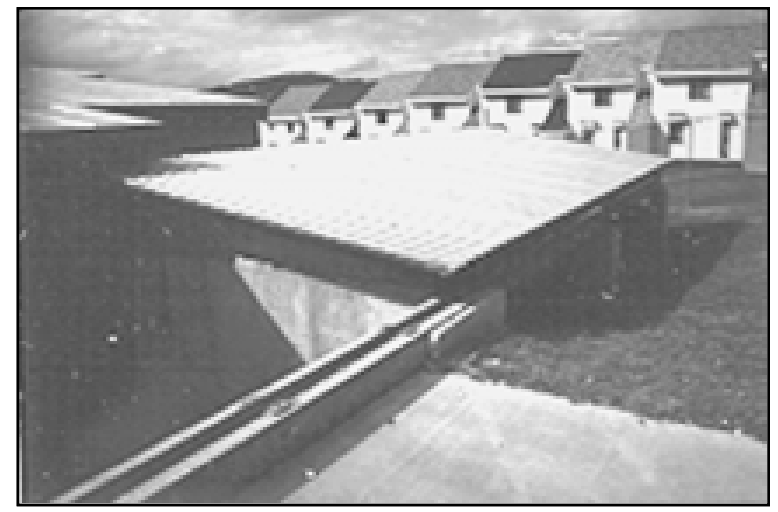

\section{Figure 13. A Bunker Storage System with Roof Retracted to Allow Fuel to be Dumped into Storage.}

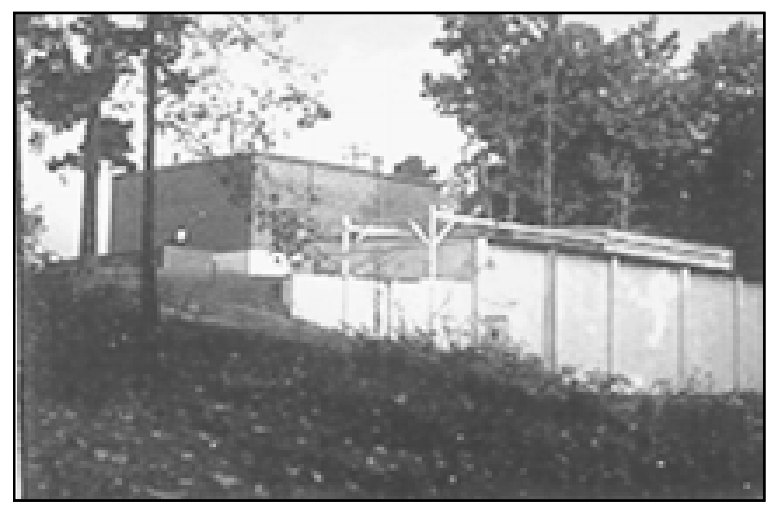

Figure 14. Another Example of a Bunker Storage System.

Figure 15 shows a commercially available enclosed metal wood storage bin. The bin includes an overhead conveyor for loading the bin and a traversing auger and a belt transfer conveyor for unloading the bin.

As discussed before, very small-scale facilities also may use live-bottom delivery trucks for fuel storage. However, this use ties up the trailer van and usually necessitates that the plant own the trailer vans. Some small-scale facilities have permanently installed live-bottom van beds in their plants to store and feed fuel. In most cases, these vans are mounted below ground level, so that incoming dump trucks or live-bottom trailers can empty directly into the permanently mounted van bed. Figure 16 shows an example of a live-bottom truck bed used as a permanently mounted fuel bin. 


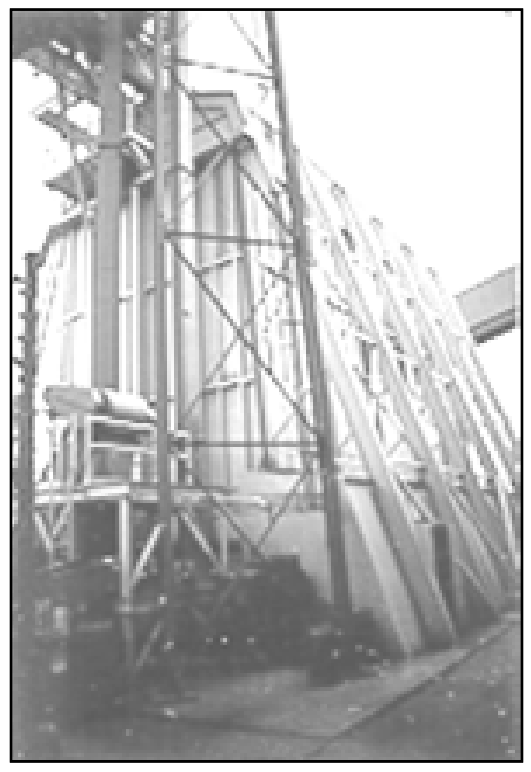

Figure 15. An Enclosed Metal Bin with a Traversing Auger Unloader.

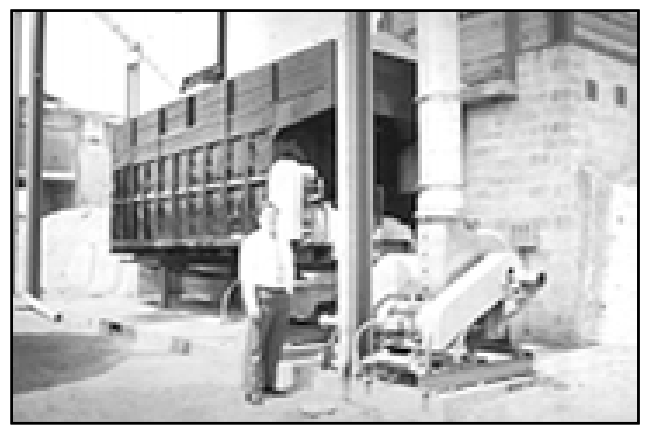

Figure 16. An Example of a Live Bottom Truck Bed Used as a Permanently Mounted Fuel Bin.

Intermediate-scale facilities are more likely to use open-shed storage systems, which afford some protection but are not as expensive as hoppers or bins (Figure 17 and 18). Covered storage systems are usually desired when dry fuel is available, in order to take advantage of the increased energy content and combustion efficiency afforded by dry fuel. Open shed systems also allow easy access for a front-end loader, which is the least expensive method for moving fuel (Schmidt, 1991). 


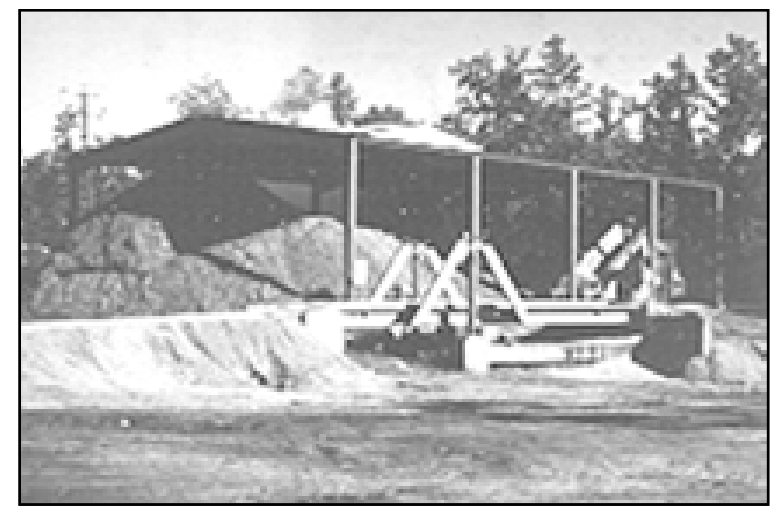

Figure 17. An Open Shed Wood Storage System with a TrailerOnly Dumper in the Foreground.

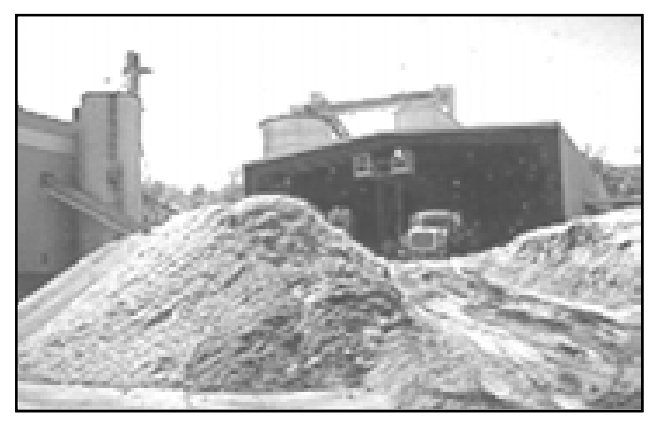

Figure 18. An Example of Silo, Open-Shed, and Open-Pile Wood Storage Systems Used Together at One Site.

The radial stacker loader is a version of an open-pile storage system used at smaller and intermediate scales. This system uses a cleated belt conveyor with its lower end anchored at a pivot point and a frame on wheels that allows the inclined conveyor to swing in a 175 degree arc, thus creating a linear pyramid-shaped woodpile in the form of an arc (Figure 19). Depending on the processing system configuration, the conveyor to the stacking conveyor would come from either the truck dump or disc scalping-hog operations. Conveyor lengths of 15 to $20 \mathrm{~mm}$ are available with maximum inclines of 20 degrees. A radial stacker loader with a $15 \mathrm{~m}$ long belt has a discharge height of $7.5 \mathrm{~m}$ and can store 900 tonnes or $2500 \mathrm{~m}^{3} \mathrm{cf}$ of wood waste (West, 2002). 


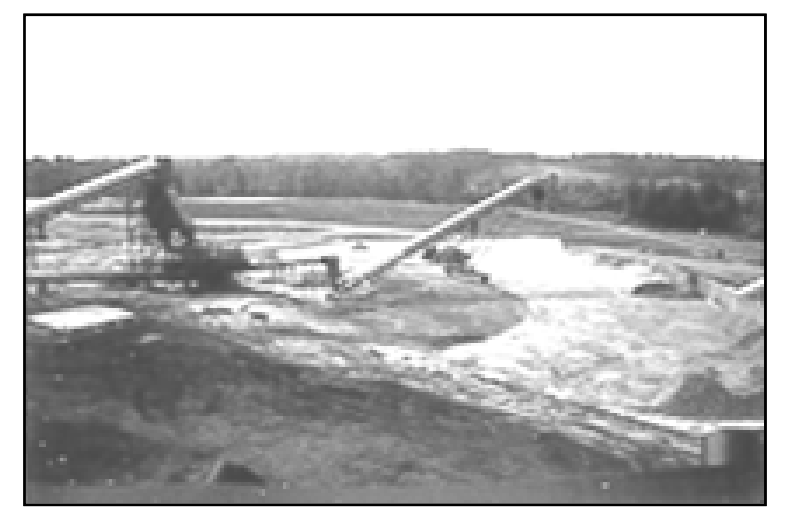

Figure 19. An Example of a Radial Stacker Loader with the Storage Currently Empty.

Open, uncovered piles provide the greatest storage volume at the lowest cost (GLRBEP, 1986).

Large-scale facilities are more likely to use open piles, especially to store wet or green fuels, unless climatic conditions dictate covered storage (Figure 20). Pads for storage piles are a necessity to prevent the introduction of rocks and soil and absorption of groundwater. Pads need to be sloped away from the pile to facilitate run-off. Concrete is recommended for smaller pads, asphalt can be gouged by front-end loaders.

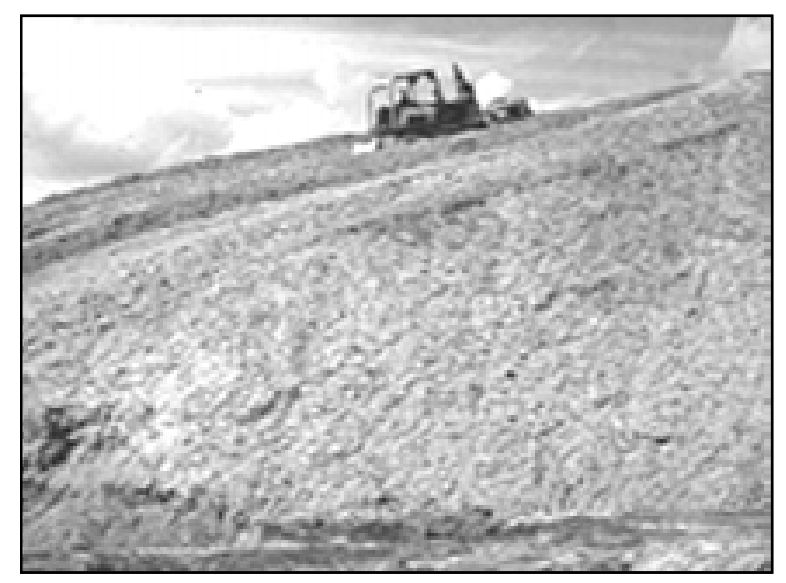
Figure 20. A Very Large Open-Pile with Bulldozer
Managing the Pile.

Larger pads are constructed of leveled earth with a crushed rock base. One developer of biopower plants in the range of 10 to $50 \mathrm{MW}$ constructs earthen pads for wood storage with a base of $150 \mathrm{~mm}$ crusher run, followed by $50 \mathrm{~mm}$ of gravel, plus $25 \mathrm{~mm}$ of sand sealer leveled over the top and then rolled. A 150 to $300 \mathrm{~mm}$ layer of wood is left on top of soil to prevent scalping of soil and $7.5 \mathrm{~mm}$ by $7.5 \mathrm{~mm}$ concrete pads are placed at the truck dumper and feed hopper, where wear from the front-end loader could create problems (Brammer, 2002). 
Open storage of wood in conical or tent-shape configurations minimizes water penetration from rainfall. Open pile storage depths up to $15 \mathrm{~m}$ are not uncommon (Donovan, 1994); however, it is difficult to pile higher than $6 \mathrm{~m}$ with a wheeled front-end loader, and environmental regulations may prevent piles higher than $9 \mathrm{~m}$ due to wind-blown debris (Brammer, 2002).

Removal from storage. The method of retrieving wood from storage depends on the method of storage, the volume that must be moved, cost of the retrieval systems, as well as operating and maintenance requirements. Bins or hoppers may be live-bottom for retrieval or may use an auger. Bins, hoppers, and silos may have a chain flail mounted on a vertical shaft in the center to prevent bridging. Elevated bins or hoppers can use at least some gravity flow to facilitate retrieval.

Reclaiming from bins or hoppers is usually done by gravity. A Canadian company has developed the moving hole feeder which relies entirely on gravity to discharge material via one or more "moving holes" or slots along the full length of the bin (Figure 21). As the deck is traversed back and forth by one or more hydraulic cylinders, the belts on the deck are held stationary relative to the stored material, thus allowing frictionless moving holes. The lack of friction between the stored material and the feeder deck avoids any compaction of the material. The moving holes traverse the entire outlet area, resulting in a fully effective discharge of the entire contents of the bin. This system provides a first-in-first-out flow pattern, and steady, consistent discharge of material, providing good metering even from the large storage bins; and allows use of tall storage bins, which provide economical storage of large volumes of material (Bundalli, 1998).

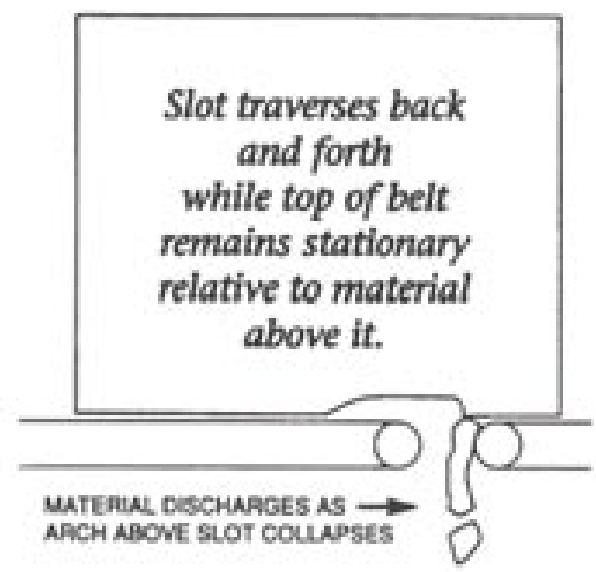

Figure 21. The Concept of the Moving Hole Feeder.

Covered-pile storage areas frequently have at least one side of the building enclosed. Sometimes a reclaimer is mounted along the base of the pile to automatically retrieve fuel and place it onto a conveyor. A reclaimer is usually in the form of a drag chain or a large horizontal auger, which may move in a circular motion around a central pivot point or along tracks in a linear motion. A linear auger is preferred for access to the drive end of the auger for maintenance purposes.

Front-end loaders are also used for fuel retrieval in large open piles or open shed storage systems. 
Conveying. The type of conveyor used depends on the characteristics of the woody material; the degree of elevation, if any, involved; conveyance distance; maintenance requirements; and capacity requirements. Conveyance equipment can include front-end loaders; pneumatic, screw, belt, and drag/flight chain conveyors; oscillating conveyors, and bucket elevators (Schmidt, 1991); and, in general, can be classified as mechanical or pneumatic (GLRBEP, 1986).

Although conveyors may seem a relatively minor component of wood energy systems, their operation and reliability is crucial to move wood between processing stations to the conversion device. As such, the selection of the proper conveyor for the application involved, and sizing it correctly is crucial. It is important to have accurate information on the fuel-feed requirements of the conversion device before purchasing conveying equipment. Table 3 lists the advantages and disadvantages of the various types of conveying equipment.

Table 3. Advantages and Disadvantages of Wood Fuel Conveying Systems (GLRBEP, 1986; Makansi, 1980)

\begin{tabular}{|l|l|l|l|}
\hline \multicolumn{1}{|c|}{ Type } & \multicolumn{1}{|c|}{ Cost } & \multicolumn{1}{c|}{ Advantage } & \multicolumn{1}{c|}{ Disadvantage } \\
\hline Belt conveyors & $\begin{array}{l}\text { Highest capital } \\
\text { cost/energy efficient }\end{array}$ & Any type of fuel & $\begin{array}{l}\text { Limited to } 15^{\circ} \text { incline, } \\
\text { light dry particles, } \\
\text { easily blown off }\end{array}$ \\
\hline Screw conveyors & $\begin{array}{l}\text { High capital } \\
\text { cost/energy efficient }\end{array}$ & $\begin{array}{l}\text { When site space is a } \\
\text { premium, easily used } \\
\text { on inclines }\end{array}$ & $\begin{array}{l}\text { Not applicable for } \\
\text { large pieces or stringy } \\
\text { wood }\end{array}$ \\
\hline Chain/drag conveyors & $\begin{array}{l}\text { Medium capital } \\
\text { cost/energy efficient }\end{array}$ & $\begin{array}{l}\text { Rugged and } \\
\text { adaptable to plant } \\
\text { conditions }\end{array}$ & $\begin{array}{l}\text { High maintenance, } \\
\text { possible fire hazard, } \\
\text { limited to 18 } \text { inclines }\end{array}$ \\
\hline Bucket conveyors & Medium capital cost & $\begin{array}{l}\text { Applicable for inclines } \\
\text { and vertical transport }\end{array}$ & $\begin{array}{l}\text { Not suitable for long } \\
\text { horizontal runs }\end{array}$ \\
\hline Oscillating conveyors & $\begin{array}{l}\text { Low capital } \\
\text { cost/energy efficient }\end{array}$ & $\begin{array}{l}\text { Dense, bulky and } \\
\text { stringy wood fuels, } \\
\text { horizontal transport }\end{array}$ & $\begin{array}{l}\text { Not applicable for } \\
\text { small light fuels such } \\
\text { as sawdust limited } \\
\text { incline }\end{array}$ \\
\hline Pneumatic conveyors & $\begin{array}{l}\text { High operating } \\
\text { (energy) cost }\end{array}$ & $\begin{array}{l}\text { Small, lighter fuels, } \\
\text { i.e., finely hogged dry } \\
\text { waste, sawdust and } \\
\text { sanderdust, long } \\
\text { distances }\end{array}$ & $\begin{array}{l}\text { Not applicable for } \\
\text { larger particles } \\
\text { fugitive dust problems }\end{array}$ \\
\hline
\end{tabular}

Belt conveyors, which are the least expensive conveyor and have the lowest energy requirement, are probably the most commonly used conveyors. Belt conveyors are used to transport virtually all types of wood fuels, including densified fuels. These conveyors consist of a rubber belt that operates in a loop supported on rollers, usually in a U-shaped frame to allow them to carry large amounts of wood (also called trough-idler belt conveyors). Sometimes elastic sidewalls and flights are added to increase capacity and to allow use on inclines. Maximum recommended incline is usually 15 degrees. Outside belt conveyors should be covered to reduce potential dust, moisture pickup, and ice formation problems. 
Screw conveyors or augers are used for elevating or metering fuel into the conversion device-their two biggest advantages over other types of conveyors, especially belt conveyors. They are also sometimes used to reclaim fuel from storage systems. However, screw conveyors are relatively expensive, can only transport materials in a straight line, have high wear, and may jam frequently. Screw conveyors have trouble handling stringy materials or wood fuel particles larger than $50 \mathrm{~mm}$ square. They are usually mounted in an open-topped, U-shaped trough to allow access to the material in case of jamming and to minimize jamming.

Chain conveyors can consist of large box-links, which serve as the conveyor flights, or can consist of single or double chains with flights. In all cases the flights lie in a trough, which contains the material during transport. These conveyors are versatile and rugged. Their primary applications are in livebottom equipment and for feeding fuel to a conversion device. In some cases, chain conveyors are used to meter fuel into the conversion device. Chain conveyors are less sensitive to load variations and overloading than belt conveyors, their operational energy requirements are relatively low, and their cost falls between belt and screw conveyors. Properly designed drag chain systems can move material up slopes of up to 18 degrees, but have high wear and maintenance requirements (Makansi, 1980). Flight conveyors are suitable for inclines up to 30 degrees. Neither drag chains nor flight conveyors are recommended for applications exceeding $15 \mathrm{~m}$ in length, although this is sometimes exceeded in practice (Makansi, 1980).

Bucket conveyors are used when vertical lift is required, space is at a premium, and the particles to be moved are relatively small and uniform. The operational energy requirements for bucket conveyors are relatively low, but they have higher than average maintenance costs, and a higher initial cost. Nevertheless, it remains the most economical way to convey materials that only have to be moved vertically.

Oscillating conveyors are trough-shaped and can handle a wide variety of fuels without jamming. These conveyors transport material by rapidly moving the trough in upward and forward motions. They are generally limited to conveying over short distances and to horizontal applications.

Pneumatic conveyors are used to move small, light wood particles such as sawdust and sanderdust and consist of a positive displacement blower, transport piping, a rotary airlock to inject fuel into the pipe, and a cyclone to separate the fuel from the conveying air at the terminal end. The cyclone can be eliminated if the system is feeding fuel into a suspension-fired boiler.

Pneumatic systems can move material vertically, horizontally, or up inclines; are more flexible in arrangement than mechanical conveyors, and are usually less costly to install. Their best use is for distances exceeding $150 \mathrm{~m}$ (especially if straight runs) and where the conversion device is a suspension burner. Pneumatic conveyors are noted for having high energy requirements (roughly 10 times that of belt conveyors) and wearing rapidly, especially if non-wood materials are present (Makansi, 1980). The energy requirements and wear also increase dramatically as the particle size of the conveyed material increases. Furthermore, depending on fine particulates present and environmental regulations, a secondary dust collection system may be required after the cyclone.

A major benefit of a pneumatic system is that it dries the product during conveyance. An estimate of this benefit is that a typical pneumatic system conveying 50\% moisture content wood will remove $3 \%$ of the moisture, with removal of as much as $6 \%$ possible. Power system costs are recovered by removing $1.5 \%$ of the moisture (Makansi, 1980). 
Front-end loaders are usually rubber-tired tractors with over-sized buckets for handling large volumes of low density material. They are used in a variety of ways in a wood fuel yard to place wood into storage, retrieve it, and carry it to a feed hopper for the conversion device.

Dryers. Before any fuel can burn, any inherent moisture must be evaporated. Dry fuel can increase the flame temperature and increase the overall thermal efficiency in combustion devices.

Nevertheless, in many cases it does not pay to install a dryer, but instead let the conversion device perform the drying as it converts the fuel to thermal forms of energy. Although this lowers the efficiency of the conversion device, it is usually the most economical way to dry the fuel.

Dryers have significant capital and O\&M costs associated with them, and are usually not used except where the fuels are very green or the conversion device requires them (e.g., suspension burners). In the latter case, proper design procedures would dictate that that the conversion device is chosen with the fuel characteristics in mind. Thus if small, dry particles as required for suspension burners were readily available, then a suspension burner would be chosen. However, if green fuels were the predominant resource available, then a stoker or other type of appropriate device would be chosen. In some cases, though, fuel sources change after the system has been installed, thereby necessitating changes in the fuel preparation, including the need for drying.

The advantages of a drying system must be weighed against its costs. Stack gases may provide a source of waste heat; however, these gases have high humidity, relatively low temperatures (175 to $260^{\circ} \mathrm{C}$ ), and can be corrosive. One advantage of using stack gases is their low oxygen content, which tends to prevent or suppress accidental fires in the dryer.

Rotary drum dryers, due to their simplicity and relatively low cost compared to other dryer types, are the most predominant type used in the industry (Figure 22). These dryers tumble the material in a rotating, slightly inclined drum in the presence of heated air. The rotation continually exposes particles to the hot air and the slight incline and internal flighting serves to move the material by gravity toward the discharge end. Sometimes positive or negative air pressure is used to move the material through the dryer. Rotary drums may have two or more concentric drums to increase the residence time and provide for multiple passes of the air and material to increase drying efficiency and rate. Dryers can be set up to operate from natural gas, fuel oil, propane, or wood fuels.

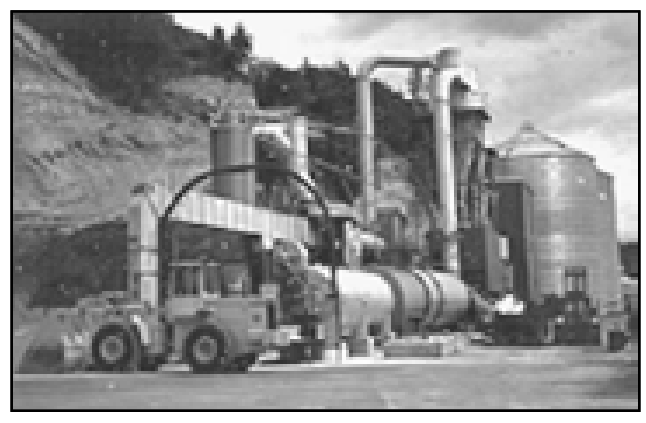

Figure 22. A Front-End Loader, Rotary Dryer, and Metal Silo Storage System. 
Rotary drum dryers are not sensitive to wood particle size and can utilize air temperatures up to $870^{\circ} \mathrm{C}$. Residence time and air temperature can be easily controlled to control fuel moisture content. However, rotary drum dryers can create a fire or explosion hazard if a spark ignites dust in the dryer. If flue gas is used as the hot air source, sparks may also be carried over in the gas and create a fire or explosion hazard. Measures to prevent fire and explosion include cutting off fans and blowers, injecting steam, stopping fuel input, and other measures (GLRBEP, 1986).

The suspension dryer is the second most commonly used dryer. The major components of a suspension burner are an induced draft fan, flash tube or mixing chamber, and a system to separate the gas and solids exiting the dryer (Figure 23). In operation, green fuel is blown into a separator/collector pneumatically with a stream of hot air. Due to the pneumatic conveyance and lower air temperature, particle size is more critical than with rotary drum dryers. Suspension dryers are vertically oriented and are relatively small, thus they are more frequently used for retrofit applications (GLRBEP, 1986).

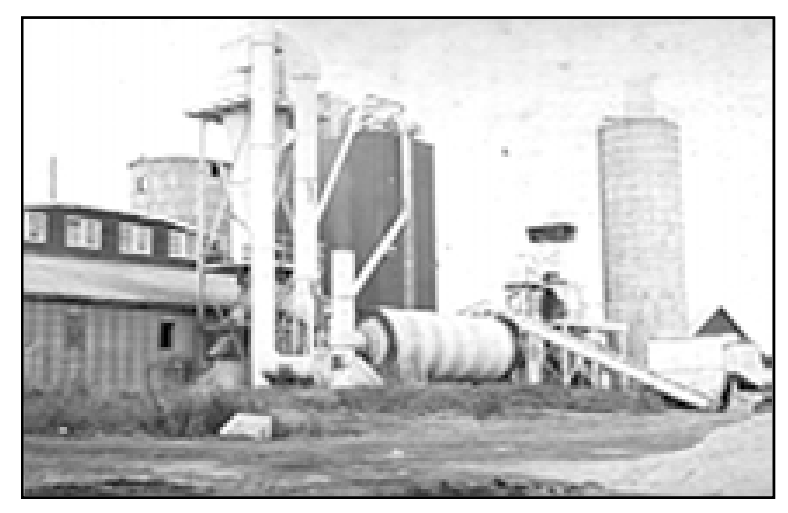

\section{Figure 23. A Rotary Drum Drying System Showing Ducting and Particulate Capture System.}

Two other types of dryers are infrequently used - the hot hog and hot conveyor. The hot conveyor moves fuel countercurrent to a stream of hot gas or has a hot bed for heat transfer. Both oscillating and flight type conveyors are used and are sometimes enclosed to improve their efficiency. The hot hog is similar to a conventional hog, except hot air is forced through the device while it is operating so that it simultaneously shreds and dries. Both systems are considered to have high maintenance costs and to be relatively ineffective. 


\section{ENVIRONMENTAL FACTORS}

Environmental factors associated with processing wood include noise, solid waste disposal, air emissions, water pollution, and facility aesthetics.

Noise. In addition to facility employees, noise that is noticeable and objectionable to neighbors, especially residential neighbors, is a concern. OSHA requirements mandate that hearing protection must be provided at noise levels above 85 decibels (Goldstein, 2001) and local ordinances may have lower requirements or restrictions on operating hours. For example, the City of St. Petersburg, Florida, has a noise abatement ordinance that specifies that between the hours of 8:00 am and 6:00 pm noise levels shall not exceed 75 decibels at the nearest property line, or 75 decibels from 7:00 am to 6:00 pm at the commercial property line (Goldstein, 2001).

Noise comes from grinding operations and other operations, such as conveyors, that have moving parts. Front-end loaders can also contribute to noise levels. Noise that varies in intensity is of greater concern than noise that is of constant volume, unless the noise is extremely loud or high-pitched. Solutions for noise mitigation include siting the plant with a buffer strip to isolate the operation from any neighbors, limiting operations to daylight hours, and sound-proofing the primary noise components-especially the grinder. Other solutions include the construction of sound barriers of concrete, earth, or mulch and vegetative buffer strips. Setting the grinder on the ground instead of a concrete pad and use of electric motors can also help control noise. Operation of equipment at the lowest permissible RPM is sometimes also recommended by equipment vendors for noise control (Goldstein, 2001).

Earplugs and earmuffs can be used to protect facility employees. Shields around noise-generating equipment (e.g., engine enclosures) or the operators (e.g., enclosed cabs) and mufflers are also means to reduce noise levels and protect employees.

Solid Waste. Solid waste disposal issues stem from non-wood materials brought to the plant (e.g., rocks, metals) and wood that is commingled with non-wood materials and thus may not be cost effective to separate. Sometimes, excessively large or knotty pieces of wood are also disposed of instead of reprocessing them. The typical means of disposal of such materials is to haul them to a landfill. Since these materials are inert, an inert landfill can be used. An exception is treated wood or other hazardous materials, which require special handling and disposal requirements.

Other solid wastes can include sludges from scrubbers associated with dust collection or dryer emissions. Unless permitted for land application, sludges must be disposed of by incineration or by placing in a landfill meeting US Environmental Protection Agency RCRA Subtitle D requirements, unless hazardous in nature (EPA, 1999).

Air Emissions: Dust. One air emission from processing is fugitive dust. Dust generated from truck traffic and unloading, screening, conveying, and all operations except grinding are of little concern unless they cause an obvious problem. If dust is a problem, it is associated with very dry climates, windy conditions, and fine, dry wood waste. Enclosing unloading and other processing operations, especially storage systems, can prevent fugitive dust, but may require installation of dust collection systems. Excessive dust levels in enclosed structures can pose a health and explosion hazard. 
Grinding is the primary source of dust and results from grinding excessively dry materials. The main method of controlling dust emissions from grinding is to spray water onto the material before, in, and after the grinder. Excessively dry woodpiles are also sometimes sprayed with water to minimize windblown fugitive dust emissions (Donovan, 1994). Vegetative windbreaks are occasionally used to reduce windblown dust emissions. No regulations pertaining to dust emissions were located among the federal or state authorities queried by the author, although the $90 \mathrm{MW}$ plant at Hurt, Virginia, was forced to limit its woodpile height to $9 \mathrm{~m}$ to minimize wind-blown debris.

Air Emissions: VOCs. Emissions of Volatile Organic Compounds (VOCs), which are known carcinogens, can result from drying operations, depending on wood type and drying temperatures. These volatiles form a characteristic blue haze. Remedies include minimizing emissions by using lower drying temperatures and cleaning the emissions in the exhaust air. Temperatures need to be kept below $340{ }^{\circ} \mathrm{C}$ to prevent pinewood and most hardwoods from releasing VOCs during drying. Some hardwoods can be dried at temperatures approaching $370{ }^{\circ} \mathrm{C}$ without significant release of VOCs (Ekberg, 2002).

Emissions from dryers can be controlled by thermal oxidation processes-achieved by heating the dryer exhaust gases with air to high temperatures, usually to around $870{ }^{\circ} \mathrm{C}$. Sometimes catalysts are used to allow the oxidation to occur at lower temperatures. Biofilters and adsorption systems are also sometimes used (Milota, 2000).

Water pollution. Water pollution from run-off occurs where wood is exposed to rain; this pollution falls under stormwater regulations. Management of stormwater is up to state officials with each situation permitted separately. In general, the permit will be based on the amount of wood in storage, how it is stored, the length of time stored, and where it is stored. Some environmental monitoring may also be required. In Alabama, for example, any effluent from the property would have to be monitored for total suspended solids and BOD (Phillips, 2002).

The $90 \mathrm{MW}$ biopower plant at Hurt, Virginia, requires 4 ha for wood storage. An associated system to collect and neutralize the tannic acid in the rainwater runoff cost $\$ 350,000$ to construct (Brammer, 2002).

Fires. Wet or green fuels can spontaneously combust or have excessive biological degradation. Following first-in, first-out (FIFO) procedures will minimize storage time for fuels. Methods to reduce the risk of spontaneous combustion include avoidance of excessively wet fuels or mixing green and dry fuels, limiting time in storage, and limiting pile heights to $5 \mathrm{~m}$ or less (Schmidt, 1991). Fire from non-spontaneous sources is also a risk. Maintaining $6 \mathrm{~m}$ fire lanes between piles and limiting storage pile volume are fire containment methods sometimes used.

Aesthetics. Aesthetics is not a major concern, but can make the difference between neighborhood acceptance and rejection. As a rule, an operation that is kept clean and orderly generates acceptance among neighbors and minimizes their complaints about environmental issues in general. 


\section{SYSTEM CONFIGURATIONS}

As covered in previous sections of this report, in addition to cost, several factors affect system configurations and equipment choices. Initial wood characteristics affect grinding, drying, storage and handling choices. Conversion device requirements affect drying and grinding requirements. Supply security and fuel moisture content affects storage size requirements. System capacity and environmental considerations are other factors.

Figure 24 depicts the simplest onsite wood processing system, which is used in small-scale applications in order to keep capital costs down. In this system, trucks are not weighed at the site and either self-unloading vans (dump trucks or live bottom trailers) or regular vans with Bobcat unloaders are used. The trucks empty directly into a fuel bin or hopper that is set below ground to facilitate unloading (Figures 13 and 14). The bin has a live bottom to move the fuel to a conveyor, which takes the fuel directly to the conversion device.

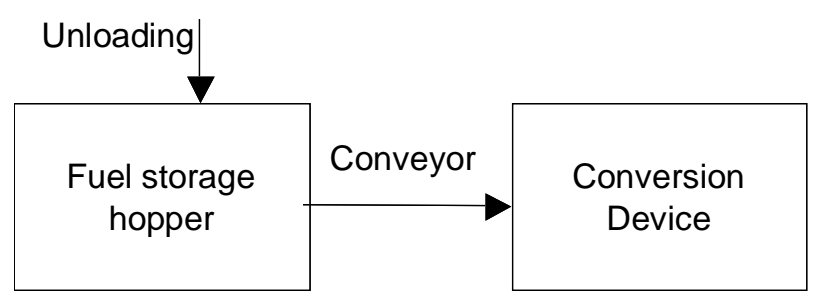

Figure 24. The Simplest Handling System.

This method requires that only wood free from non-wood materials and already processed to specification (particle size, moisture content) be delivered to the plant site. Since this method places the responsibility for fuel quality on the fuel provider, and if self-unloading trucks provided by the supplier are used, the fuel provider commands a higher price. It also places greater risk on wood quality since there is no onsite check of all fuel for non-wood materials or oversize materials that may damage the conversion device.

Figure 25 depicts a second simple wood processing system that has characteristics similar to the simplest handling system. In this system, trucks are not weighed at the site and self-unloading vans or dump trucks are used. The trucks empty directly onto a concrete slab, and a front-end loader is used to move the fuel into a building for storage and from storage to the conversion device feed hopper (Figure 26). The building may be enclosed or partially enclosed. This system may be used for smaller-scale operations where land area is not a problem.

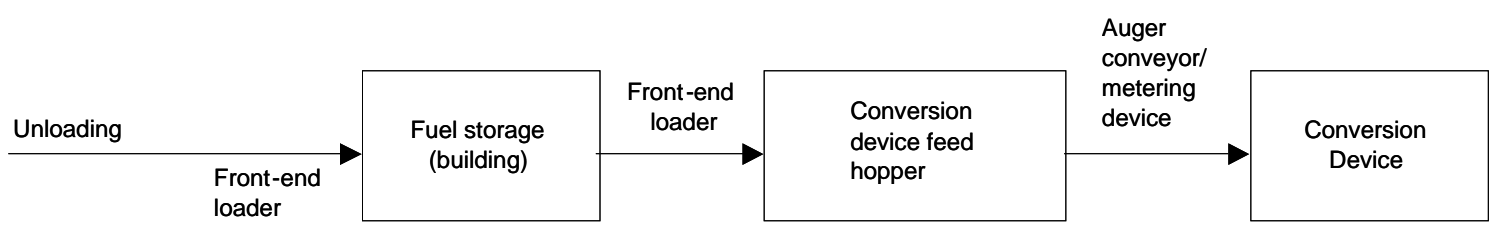

Figure 25. The Second Type of Handling System. 


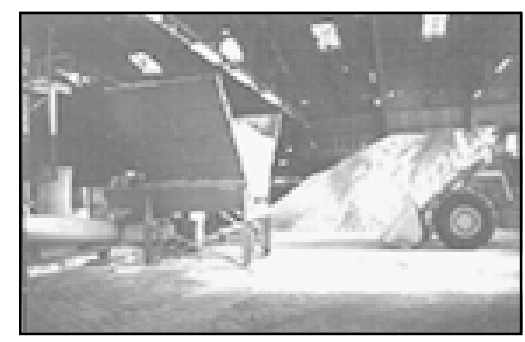

\section{Figure 26. A Front-End Loader, Storage Pile in Building, and Feed Hopper with Live Bottom.}

Figure 27 depicts a third type of wood processing system, which is similar to the second but utilizes a silo or bin for fuel storage. In addition to the previous components, this type of storage necessitates a feed hopper and conveyor system to load the wood into the bin or silo. This system would be used for smaller-scale operations where land area is limited. Hoppers and bins are also used for dry materials or for fine materials that could cause fugitive dust emissions. Figure 28 depicts a type of processing system that is similar but has scales to weigh incoming trucks.

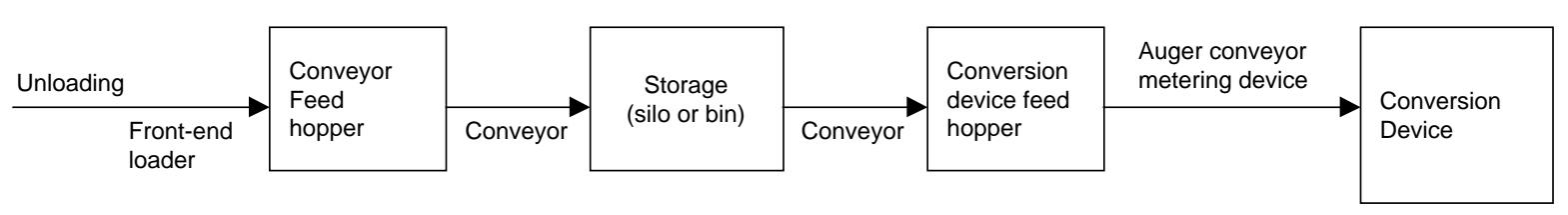

Figure 27. The Third Type of Handling System.

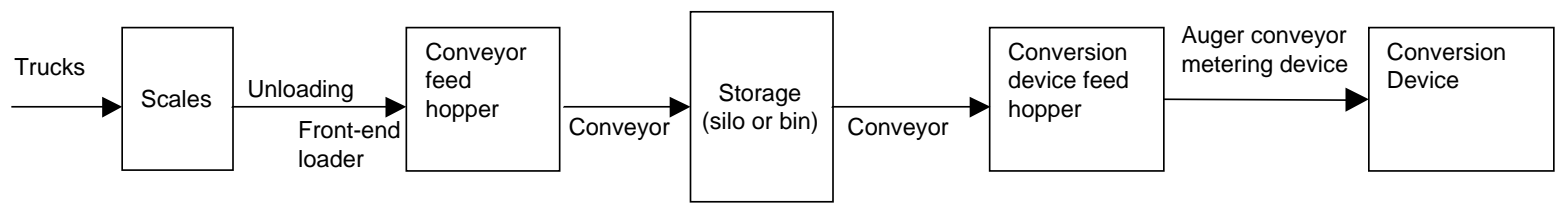

Figure 28. The Fourth Handling System with Scales Added.

Figure 29 depicts the fuel processing used for intermediate scale systems and/or for dirty fuels. This system incorporates a scale, trailer-only dumpers, magnet and non-ferrous metal detector, disk scalping screen to remove oversize materials, a hog to grind oversize materials, and open pile storage. The scalping screen reduces the loading on the grinder, saving on both capital and operating and maintenance costs. 


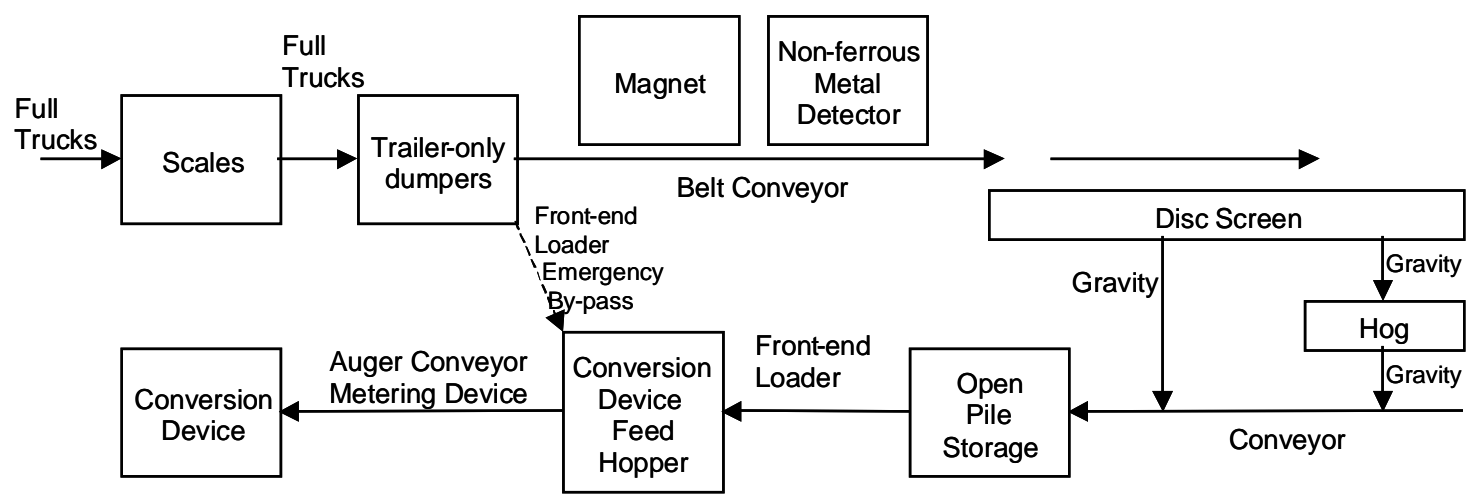

Figure 29. Handling System for Intermediate Scale Systems and Dirty Fuels.

A front-end loader is used to manage the pile and move fuel to the feed hopper of the conversion device. The front-end loader is also used in an emergency mode to move fuel directly from the truck dump to the feed hopper in case other components break down. The system shown in Figure 29, except with one or more whole-truck dumpers, is also used for large-scale facilities. An example of a wood-fired facility using this layout with a single whole-truck dumper is the 7MW equivalent woodwaste fired boiler at Jack Daniels Distillery in Lynchburg, Tennessee. An example of a system using this layout with multiple whole-truck dumpers is the $45 \mathrm{MW}$ wood-fired IPP at New Bern, North Carolina.

Figure 30 depicts the wood processing system at the $54.5 \mathrm{MW}$ (gross, $50 \mathrm{MW}$ net) wood (stoker) fired IPP in Burlington, Vermont, operated by Burlington Electric Company since 1984. Roughly $70 \%$ of the plant's fuel is whole tree chips, $25 \%$ mill residues, and 5\% from a local drop off center. The drop off center takes any unaltered wood such as Christmas trees and yard trimmings. Of the 11,000 tonnes per year received at the drop off center, approximately 6,600 tonnes are in the form of pallets (Irving, 2002).

The plant receives $25 \%$ of its wood by truck and $75 \%$ by rail, with rail shipment from a transfer point $56 \mathrm{~km}$ away. The purpose of rail shipment is to avoid truck traffic to the plant.

Train deliveries are by hopper car on an elevated track. For unloading, the hoppers are opened and the wood flows by gravity to areas beneath the elevated track where it is moved with front-end loaders to an open-pad storage pile. Three cars at a time can be dumped with the aid of a vibrator to assist flow. Whole-truck dumpers are used for truck deliveries and the same front-end loaders are used to move material from the truck dumpers to the storage pile.

From the woodpile a front-end loader moves material to a reclaimer, which takes the material under an electromagnet to a conveyor and disc-scalping screen, with the oversize particles to the hog. Due to the relative cleanliness of the fuel (since it is primarily whole tree chips), only 5 percent of the material is processed through the single $300 \mathrm{~kW}$ hog. From the hog, material flows to a distributing conveyor to surge bins, which hold one hour's storage (about 85 tonnes) (Irving, 2002). 


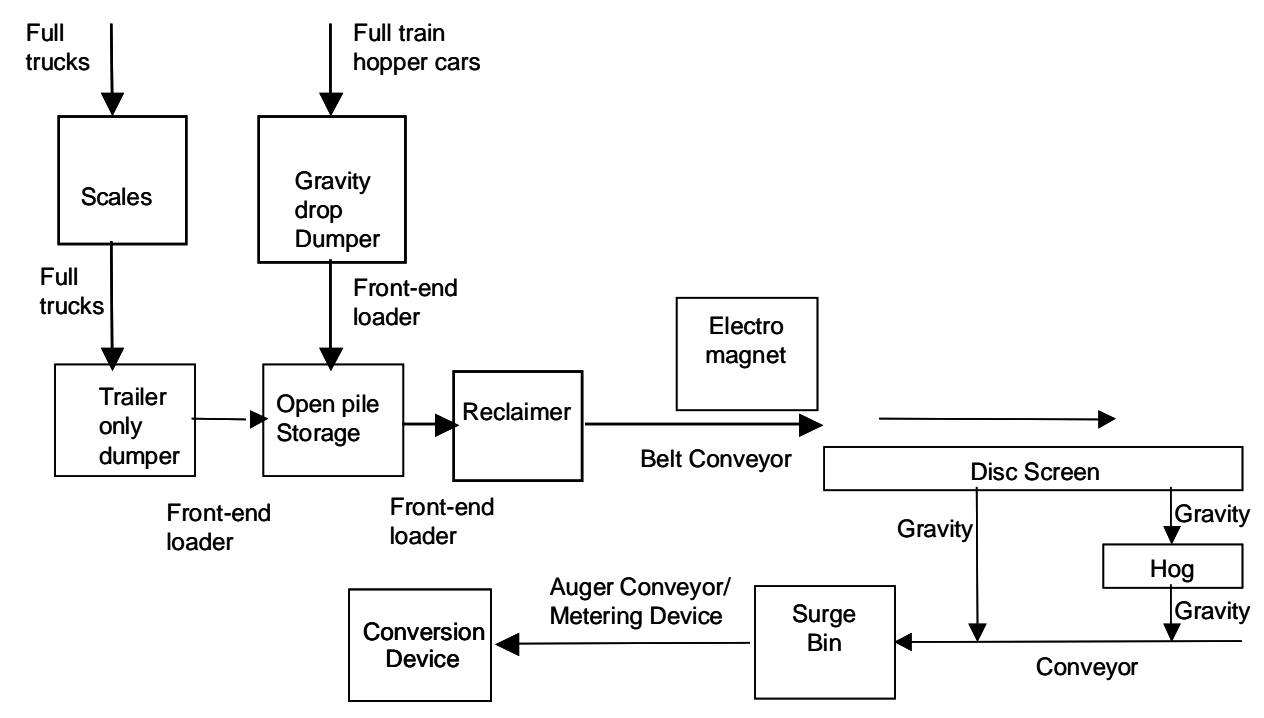

\section{Figure 30. Handling System for the 54.5 MW Wood Chip Fired Biopower Plant in Burlington, Vermont.}

Figure 31 depicts the fuel processing system used at the $90 \mathrm{MW}$ wood waste-fired (stoker) biopower plant in Hurt, Virginia, considered to be the largest wood-waste fired, independent biopower plant in the world. It involves weighing incoming loads with automated electronic scales equipped with computerized bar code readers, onsite full-truck dumpers, front-end loaders to move materials to and from storage, and open, earthen-pad woodpile storage areas. To expedite wood delivery, two truck scales are used, one for incoming loaded trucks and one for outgoing empty trucks (Figure 32).

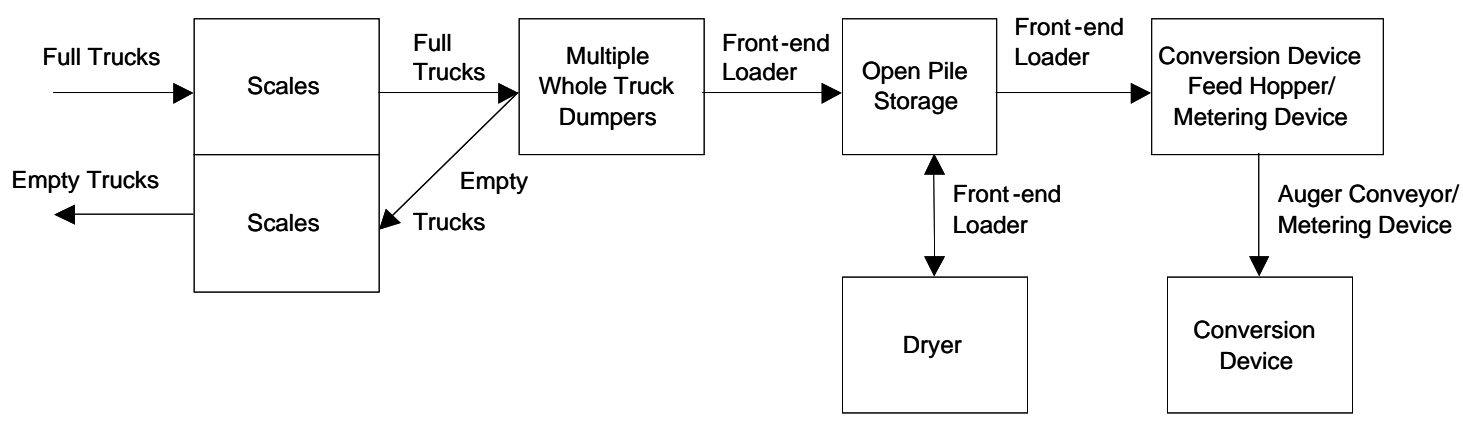

Figure 31. Handling System for the 80 MW Wood Waste Fired Biopower Plant at Hurt, Virginia. 


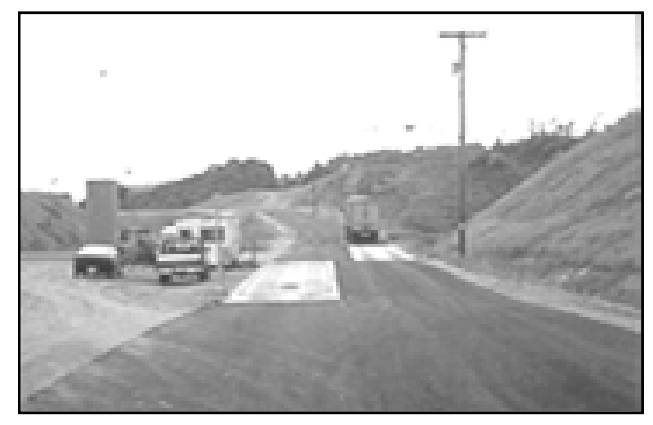

Figure 32. Separate Scales with Bar Code Scanners are Used to Weigh Incoming and Outgoing Trucks at the 90 MW Plant at Hurt, Virginia.

The Hurt plant also has a rotary drum dryer located to the side of the storage pile. Materials needing drying are moved to a separate "wet" pile upon delivery and then moved to the dryer with the frontend loader when time permits. From the dryer, the material is moved back to the main fuel storage pile containing dry material.

Note that the system does not include screens, magnets, or non-ferrous metal detectors. Thus, suppliers are required to deliver wood already processed to specification to the power plant site. Where a buyers' market exists, large facilities have the clout to require small waste generators to either conform or lose their market. 


\section{EQUIPMENT COSTS}

Tables 4 and 5 (following pages) summarize the design requirements for wood processing systems of $1,5,10,20$, and $50 \mathrm{MW}_{\mathrm{e}}$ in size with wood storage reserve of 14 and 28 days, respectively.

Assumptions are shown at the bottom of the tables. The tonnes per hour requirements in the first lines are based on the plant's size in megawatts, the heat rate (which varies depending on plant size), and the energy content of the wood (which varies with moisture content). Green wood was assumed to have a moisture content of $50 \%$ and dry wood a moisture content of approximately $10-12 \%$.

The heat rates shown in Tables 4 and 5 are for present-day stoker wood-fired boilers used for power generation and are from Ed Brammer. For much of the design criteria used here, the author is indebted to Ed Brammer, President of Asia Energy Limited (Martinsville, Virginia), and builder of several wood-fired systems in the 10 to $50 \mathrm{MW}_{\mathrm{e}}$ range, including the $90 \mathrm{MW}_{\mathrm{e}}$ (gross) wood waste fired power plant at Hurt, Virginia, now owned and operated by Florida Power and Light. Brammer constructs only facilities using conventional stoker/steam turbine systems and assumes gross heat rates of 18,972 and $16,864 \mathrm{~kJ} / \mathrm{kWh}$ for $50 \mathrm{MW}_{\mathrm{e}}$ and $10 \mathrm{MW}_{\mathrm{e}}$ systems, respectively $(14,229$ and $15,283 \mathrm{~kJ} / \mathrm{kWh}$ net heat rates, respectively).

Brammer prefers not to work with systems less than $10 \mathrm{MW}$; however, for facilities less than $10 \mathrm{MW}_{\mathrm{e}}$ he would use trailer-only dumpers. He estimates that each trailer-only dumper costs about $\$ 50,000$ installed, including $\$ 30,000$ for the concrete foundation.

Above $5 \mathrm{MW}_{\mathrm{e}}$, Brammer prefers to use whole-truck dumpers. He estimates their installed cost at $\$ 125,000$, each including $\$ 45,000$ for the concrete foundation. For facilities above $10 \mathrm{MW}_{\mathrm{e}}$ in size, Brammer uses two whole-truck dumpers. Whole-truck dumpers are used over trailer-only dumpers because the unloading time for a whole-truck dumper is half the 15-20 minutes required to unload trailer-only dumpers. Truck unloading time is especially important as the facility size increases.

Brammer uses open-pad woodpile storage systems for all plants he constructs of $10 \mathrm{MW}_{\mathrm{e}}$ and above. The earthen pads are constructed by leveling the soil, laying down $150 \mathrm{~mm}$ of crusher-run, $50 \mathrm{~mm}$ of gravel, followed by $25 \mathrm{~mm}$ of sand sealer leveled over the top and then rolled. A 250-300 mm layer of wood waste is left on top of the soil to prevent stones from mixing with the wood. Brammer uses $7.5 \mathrm{~m}$ by $7.5 \mathrm{~m}$ concrete pads only at the truck dumper site and the conversion device feed hopper. Brammer figures the cost of a three-acre dirt pad ranges from $\$ 60,000$ to $\$ 100,000$ depending on grading needed, gravel haul distance, and other factors. Concrete pads with $7.5 \mathrm{~m}$ by $7.5 \mathrm{~m}$ dimensions suitable for this application cost approximately $\$ 3,000$ each (Thornton, 2002).

The height of woodpiles is limited to $9 \mathrm{~m}$ by environmental regulations, to prevent windblown debris. In practice, it is hard to pile wood higher than $6 \mathrm{~m}$ with a front-end loader. For the cost estimates in this study, a square pad was assumed, with wood piled in a truncated, square-based pyramid. A pile height of $6 \mathrm{~m}$ was assumed for facilities of $10 \mathrm{MW}_{\mathrm{e}}$ or less and a 9-m height for facilities above 10 $\mathrm{MW}_{\mathrm{e}}$. There is an increasing safety hazard in using wheeled-type front-end loaders to pile wood at heights above $6 \mathrm{~m}$. The size of the pile was calculated based on the facility size and amount of fuel reserve. Brammer leaves a 3.5-m driveway around the base of his earthen storage pads. The dimensions shown in the table reflect this $3.5 \mathrm{~m}$ driveway.

Brammer likes to have from 2 to 4 weeks of fuel reserves, regardless of plant size. His contract for the $90 \mathrm{MW}_{\mathrm{e}}$ Hurt plant required him to have 30 days storage, requiring 4 ha of land. 


\section{Table 4. Requirements for Various-Sized Wood Fired Power Plants with 14 Days of Reserve Storage}

\begin{tabular}{|c|c|c|c|c|c|}
\hline \multirow{2}{*}{ Dry Wood } & \multicolumn{5}{|c|}{ System size, MWe } \\
\hline & 50 & 20 & 10 & 5 & 1 \\
\hline Required throughout day, $\mathrm{t} / \mathrm{h}$ & 43.9 & 17.6 & 9.9 & 4.9 & 1.0 \\
\hline Required delivery rate, $\mathrm{t} / \mathrm{h}$, if unloaded in $8 \mathrm{hrs}$ & 132 & 53 & 30 & 14.8 & 3.0 \\
\hline Total daily requirements, $\mathrm{t} / \mathrm{d}$ & 1,055 & 422 & 237 & 119 & 24 \\
\hline Storage requirements, $\mathrm{t}$ & 14,764 & 5,906 & 3,322 & 1,661 & 332 \\
\hline Low density (LD) storage requirements, $\mathrm{m} 3$ & 153,615 & 61,446 & 34,563 & 17,282 & 3,456 \\
\hline High density (HD) storage requirements, m3 & 83,790 & 33,516 & 18,853 & 9,426 & 1,885 \\
\hline LD Base dimension $w / 3.5 \mathrm{~m}$ driveway $\& \mathrm{~h}=6 \mathrm{~m}, \mathrm{~m}$ & & & 89 & 67 & 37 \\
\hline LD Base dimension $w / 3.5 m$ driveway $\& h=9 m, m$ & 147 & 99 & & & \\
\hline LD Base dimensions $\mathrm{w} / 3.5 \mathrm{~m}$ driveway, $\mathrm{m} 2$ & 21,505 & 9,727 & 7,903 & 4,445 & 1,369 \\
\hline LD Base dimension w/3.5m driveway, ha & 2.15 & 0.97 & 0.79 & 0.44 & 0.14 \\
\hline HD Base dimension w/3.5m driveway $\& h=9 \mathrm{~m}(6 \mathrm{~m} @ 10 \mathrm{MW}), \mathrm{m}$ & 112 & 77 & 62 & & \\
\hline HD Base dimension $\mathrm{w} / 3.5 \mathrm{~m}$ driveway, $\mathrm{m} 2$ & 12,654 & 5,933 & 3,815 & & \\
\hline HD Base dimension $w / 3.5 m$ driveway, ha & 1.27 & 0.59 & 0.38 & & \\
\hline \multicolumn{6}{|l|}{ Green Wood } \\
\hline Required throughout day, $\mathrm{t} / \mathrm{h}$ & 85.3 & 34.1 & 19.2 & 9.6 & 1.92 \\
\hline Required delivery rate, $\mathrm{t} / \mathrm{h}$, if unloaded in $8 \mathrm{hrs}$ & 256 & 102 & 58 & 28.8 & 5.8 \\
\hline Total daily requirements, $t / d$ & 2,047 & 819 & 461 & 230 & 46 \\
\hline Storage requirements, $t$ & 28,660 & 11,464 & 6,448 & 3,224 & 645 \\
\hline Low density storage requirements, $\mathrm{m} 3$ & 149,097 & 59,639 & 33,547 & 16,773 & 3,355 \\
\hline High density storage requirements, $\mathrm{m} 3$ & 74,548 & 29,819 & 16,773 & 8,387 & 1,677 \\
\hline LD Base dimension $w / 3.5 \mathrm{~m}$ driveway $\& \mathrm{~h}=6 \mathrm{~m}, \mathrm{~m}$ & & & 88 & 66 & 37 \\
\hline LD Base dimension $\mathrm{w} / 3.5 \mathrm{~m}$ driveway $\& \mathrm{~h}=9 \mathrm{~m}, \mathrm{~m}$ & 145 & 97 & & & \\
\hline LD Base dimensions w/3.5m driveway, $\mathrm{m} 2$ & 20,941 & 9,487 & 7,704 & 4,339 & 1,343 \\
\hline LD Base dimension w/3.5m driveway, ha & 2.09 & 0.95 & 0.77 & 0.43 & 0.13 \\
\hline HD Base dimension w/3.5m driveway $\& h=9 \mathrm{~m}(6 \mathrm{~m} @ 10 \mathrm{MW}), \mathrm{m}$ & 107 & 74 & 59 & & \\
\hline HD Base dimension w/3.5m driveway, $\mathrm{m} 2$ & 11,452 & 5,411 & 3,501 & & \\
\hline HD Base dimension w/3.5m driveway, ha & 1.15 & 0.54 & 0.35 & & \\
\hline \multicolumn{6}{|l|}{ Assumptions } \\
\hline Gross Heat Rate above $10 \mathrm{MW}, \mathrm{kJ} / \mathrm{kWh}=$ & 16,864 & & \multicolumn{2}{|c|}{ Density range } & \\
\hline Gross Heat Rate $10 \mathrm{MW}$ and below, $\mathrm{kJ} / \mathrm{kWh}=$ & 18,972 & & High & Low & \\
\hline Days storage reserve $=$ & 14 & & density & density & \\
\hline Dry wood energy content, GJ/t = & 19.19 & Dry, $\mathrm{kg} / \mathrm{m} 3=$ & 176 & 96 & \\
\hline Green wood energy content, GJ/t = & 9.89 & Grn, $\mathrm{kg} / \mathrm{m} 3=$ & 384 & 192 & \\
\hline & & & & & \\
\hline & & & & & \\
\hline
\end{tabular}




\section{Table 5. Requirements for Various-Sized Wood Fired Power Plants with 28 Days of Reserve Storage}

\begin{tabular}{|c|c|c|c|c|c|}
\hline \multirow[b]{2}{*}{ Dry Wood } & \multicolumn{5}{|c|}{ System size, MWe } \\
\hline & 50 & 20 & 10 & 5 & 1 \\
\hline Required throughout day, $\mathrm{t} / \mathrm{h}$ & 43.9 & 17.6 & 9.9 & 4.9 & 1.0 \\
\hline Required delivery rate, $\mathrm{t} / \mathrm{h}$, if unloaded in $8 \mathrm{hrs}$ & 132 & 53 & 30 & 14.8 & 3.0 \\
\hline Total daily requirements, $t / d$ & 1,055 & 422 & 237 & 119 & 24 \\
\hline Storage requirements, $\mathrm{t}$ & 29,528 & 11,811 & 6,644 & 3,322 & 664 \\
\hline Low density (LD) storage requirements, $\mathrm{m} 3$ & 307,230 & 122,892 & 69,127 & 34,563 & 6,913 \\
\hline High density (HD) storage requirements, m3 & 167,580 & 67,032 & 37,705 & 18,853 & 3,771 \\
\hline LD Base dimension $w / 3.5 m$ driveway $\& h=6 m, m$ & & & 120 & 89 & 47 \\
\hline LD Base dimension $w / 3.5 m$ driveway $\& h=9 m, m$ & 201 & 133 & & & \\
\hline LD Base dimensions w/3.5m driveway, m2 & 40,305 & 17,650 & 14,481 & 7,903 & 2,204 \\
\hline LD Base dimension w/3.5m driveway, ha & 4.03 & 1.76 & 1.45 & 0.79 & 0.22 \\
\hline HD Base dimension w/3.5m driveway $\& h=9 m(6 m @ 10 M W), m$ & 152 & 102 & 81 & & \\
\hline HD Base dimension $\mathrm{w} / 3.5 \mathrm{~m}$ driveway, $\mathrm{m} 2$ & 23,243 & 10,466 & 6,517 & & \\
\hline HD Base dimension w/3.5m driveway, ha & 2.32 & 1.05 & 0.65 & & \\
\hline \multicolumn{6}{|l|}{ Green Wood } \\
\hline Required throughout day, $\mathrm{t} / \mathrm{h}$ & 85.3 & 34.1 & 19.2 & 9.6 & 1.92 \\
\hline Required delivery rate, $\mathrm{t} / \mathrm{h}$, if unloaded in $8 \mathrm{hrs}$ & 256 & 102 & 58 & 28.8 & 5.8 \\
\hline Total daily requirements, $t / d$ & 2,047 & 819 & 461 & 230 & 46 \\
\hline Storage requirements, $\mathrm{t}$ & 57,319 & 22,928 & 12,897 & 6,448 & 1,290 \\
\hline Low density storage requirements, $\mathrm{m} 3$ & 298,193 & 119,277 & 67,094 & 33,547 & 6,709 \\
\hline High density storage requirements, $\mathrm{m} 3$ & 149,097 & 59,639 & 33,547 & 16,773 & 3,355 \\
\hline LD Base dimension $\mathrm{w} / 3.5 \mathrm{~m}$ driveway $\& \mathrm{~h}=6 \mathrm{~m}, \mathrm{~m}$ & & & 119 & 88 & 46 \\
\hline LD Base dimension $\mathrm{w} / 3.5 \mathrm{~m}$ driveway \& $\mathrm{h}=9 \mathrm{~m}, \mathrm{~m}$ & 198 & 131 & & & \\
\hline LD Base dimensions w/3.5m driveway, $\mathrm{m} 2$ & 39,213 & 17,193 & 14,101 & 7,704 & 2,157 \\
\hline LD Base dimension w/3.5m driveway, ha & 3.92 & 1.72 & 1.41 & 0.77 & 0.22 \\
\hline HD Base dimension w/3.5m driveway \& $h=9 m(6 m @ 10 \mathrm{MW}), \mathrm{m}$ & 145 & 97 & 77 & & \\
\hline HD Base dimension w/3.5m driveway, m2 & 20,941 & 9,487 & 5,937 & & \\
\hline HD Base dimension w/3.5m driveway, ha & 2.09 & 0.95 & 0.59 & & \\
\hline \multicolumn{6}{|l|}{ Assumptions } \\
\hline Gross Heat Rate above $10 \mathrm{MW}, \mathrm{kJ} / \mathrm{kWh}=$ & 16,864 & & \multicolumn{2}{|c|}{ Density range } & \\
\hline Gross Heat Rate $10 \mathrm{MW}$ and below, $\mathrm{kJ} / \mathrm{kWh}=$ & 18,972 & & High & Low & \\
\hline Days storage reserve $=$ & 28 & & density & density & \\
\hline Dry wood energy content, GJ/t = & 19.19 & Dry, $\mathrm{kg} / \mathrm{m} 3=$ & 176 & 96 & \\
\hline Green wood energy content, GJ/t = & 9.89 & Grn, $\mathrm{kg} / \mathrm{m} 3=$ & 384 & 192 & \\
\hline & & & & & \\
\hline
\end{tabular}


Rubber-tired loaders are frequently used for moving wood at larger facilities. Brammer uses rubbertired front-end loaders to move wood from the truck dumpers to the woodpile and to the conversion device feed hopper. At the $90 \mathrm{MW}_{\mathrm{e}}$ Hurt plant, Brammer has a rotary drum dryer located to the side of the woodpile. When not in use, and if green wood is present, the front-end loaders are used to move wood between the dryer and the woodpile.

The conversion device feed hopper is sized at four times the boiler requirements and has a livebottom consisting of a 300 to $355 \mathrm{~mm}$ traversing auger. Typically a trough idler belt conveyor is used to move the fuel from the conversion device feed hopper to the metering of "day bin." Brammer sizes the conversion device metering or "day bin," which is located inside the boiler house above the boiler, to sustain the boiler for two hours. Auger conveyors with variable speed direct current (DC) drives are used to meter the fuel from this metering or "day bin" to the conversion device. The rate of fuel feed is varied based on boiler steam pressure.

Different truck scales are used at the $90 \mathrm{MW}_{\mathrm{e}}$ Hurt facilities for weigh-in and weigh-out to expedite the flow of vehicles. Additionally, bar code scanners are used to read cards provided to each driver (Figure 32). Computers track the weight of wood delivered and automate the payments for wood deliveries. Electronic scales, although more expensive at $\$ 110,000$ versus $\$ 40,000$ for mechanical scales, can weigh trucks in 3-4 minutes versus 10 minutes per truck for mechanical scales.

With this background, and referring back to Tables 4 and 5, the storage requirements in the tables take into account the daily fuel requirements and the numbers of days of storage reserve needed. The total cubic meters of storage is calculated by using the densities shown at the bottom of the table to convert tonnage into cubic meters. Note in Tables 4 and 5, that due to the offsetting affects of wood density and energy content of green versus dry wood, the storage volume requirements are basically the same whether green or dry wood is used.

To calculate the base dimensions of a wood storage pile, a truncated pyramid with four equal sides, a square base, and side slopes of 45 degrees was assumed as the shape of the woodpile (Figure 33). The actual base dimension of the pad is the base dimension of the pyramid plus a $3.5 \mathrm{~m}$ perimeter driveway. The outcome agrees closely with the actual 4-ha pad storage area at the $90 \mathrm{MW}_{\mathrm{e}}$ plant (which is not shown on Tables 4 and 5). The results of these calculations were used to estimate the cost of the storage systems and equipment for the various size plants.

Table 6 summarizes the capital costs for various size systems. Although prices for most equipment are listed under each plant size, as the preceding examples show, depending on the designer, the configuration chosen, and other variables, not all equipment is necessarily used for all plant sizes or for a plant of the same size. As an example, although listed in Table 6, few biopower plants include dryers as part of their systems.

Systems of 1 and $5 \mathrm{MW}_{\mathrm{e}}$ are considered SMB systems. Less onsite processing equipment, the use of self-unloading trucks, and wood storage systems consisting of silos, bins, and/or buildings, characterize them. Systems from 10 to $50 \mathrm{MW}_{\mathrm{e}}$ are characterized by their open pile storage (except for extremely dry or small fuel particles) and facilities to dump trailer vans or whole trucks.

Although the cost of trucks was not part of this study, their cost is included here since they are part of the overall system, and different types of trucks are used depending on the biomass facility's needs. The type of truck thus indirectly figures into the onsite wood processing cost. 


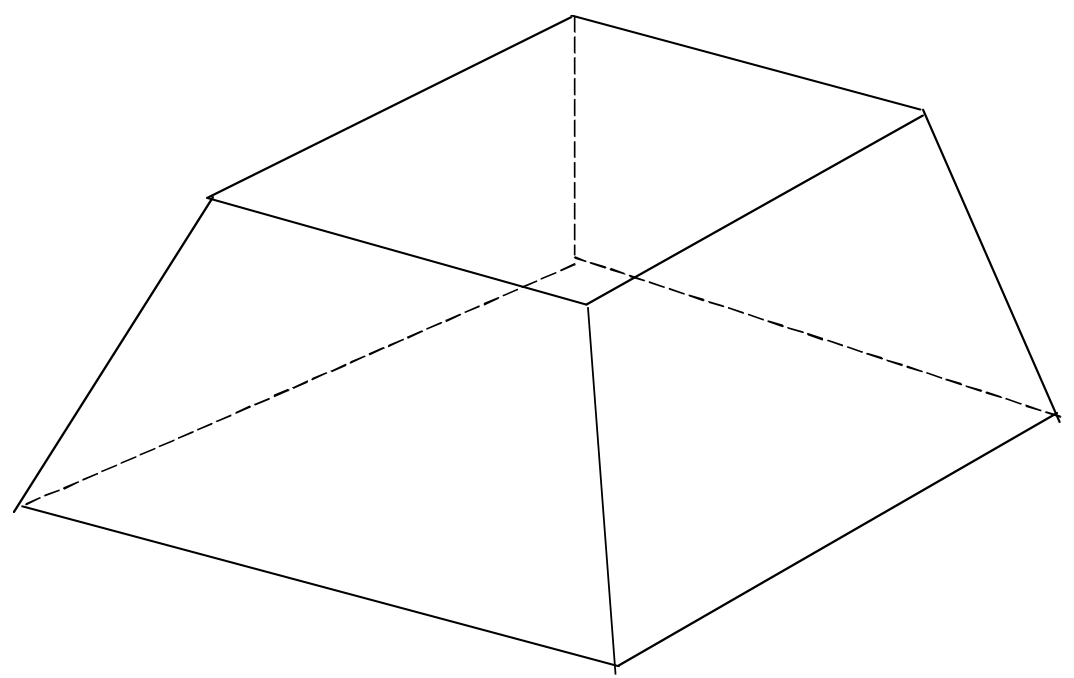

$\mathrm{V}=\mathrm{a}^{2} \mathrm{~h}$, where $\mathrm{a}=$ the average side dimension and $\mathrm{h}=$ height

$d=a+2(1 / 2 h)+2 \times 12$

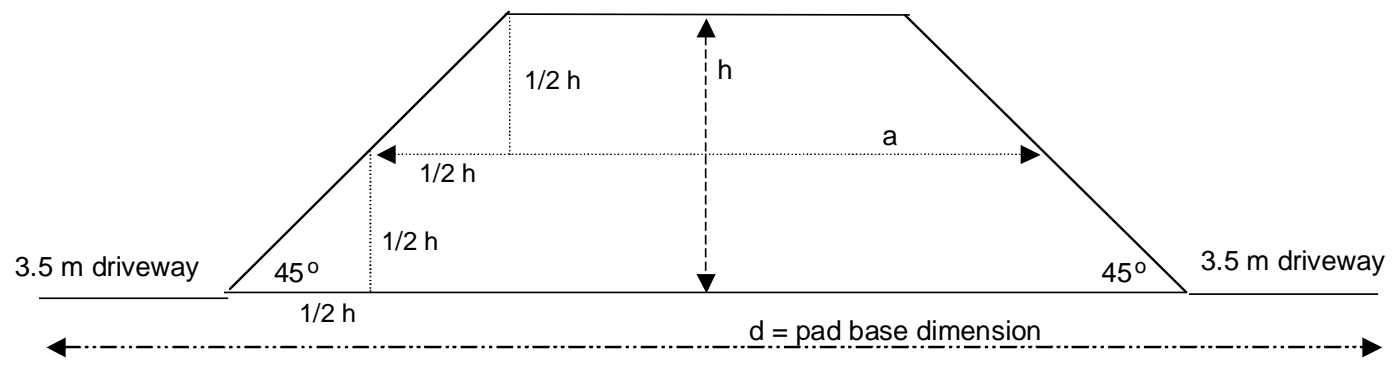

Figure 33. Calculation of Truncated Pyramid Dimensions for a Given Volume with $4^{\circ}$ Side Slopes. 
Table 6. Capital Costs Summary Table

\begin{tabular}{|c|c|c|c|c|c|c|c|c|c|c|c|c|}
\hline & \multicolumn{12}{|c|}{ System size, MWe } \\
\hline & & 50 & & 20 & & 10 & & 5 & & 1 & FN & Reference \\
\hline Truck, small dump, 12 m3 (used) & & & & & & & & & $\$$ & 40,000 & 1 & Thomas, 2002 \\
\hline Large dump trailer only, $24.5 \mathrm{~m} 3$ & & & & & & & & & $\$$ & 27,000 & & Thomas, 2002 \\
\hline Self-unloading trailer van only, $81 \mathrm{~m} 3$ & & & & & & & & & $\$$ & 40,000 & 2 & Jiles, 2002 \\
\hline Standard trailer van only, $80 \mathrm{~m} 3$ & $\$$ & 24,000 & $\$$ & 24,000 & $\$$ & 24,000 & $\$$ & 24,000 & $\$$ & 24,000 & 3 & Jiles, 2002 \\
\hline Scales, mechanical & $\$$ & 40,000 & $\$$ & 40,000 & $\$$ & 40,000 & $\$$ & 40,000 & & & & Brammer, 2002 \\
\hline Scales, electronic & $\$$ & 110,000 & $\$$ & 110,000 & $\$$ & 110,000 & $\$$ & 110,000 & & & & Brammer, 2002 \\
\hline Bar code scanner/computer system & $\$$ & 10,000 & & & & & & & & & & Brammer, 2002 \\
\hline Whole truck dumper w/ hopper & $\$$ & 604,000 & & & & & & & & & 4 & Farley, 2002 \\
\hline Truck trailer-only dumper w/ hopper & & & $\$$ & 234,000 & $\$$ & 234,000 & $\$$ & 234,000 & & & 5 & Farley, 2002 \\
\hline Scalping disk screen & $\$$ & 30,900 & $\$$ & 30,900 & $\$$ & 24,750 & $\$$ & 19,100 & $\$$ & 19,100 & 6 & West, 2002 \\
\hline Hammermill (hammer hog) & $\$$ & 59,625 & $\$$ & 59,625 & $\$$ & 50,025 & $\$$ & 49,050 & $\$$ & 49,050 & 7 & West, 2002 \\
\hline Enclosed metal bin w/ unloader & & & & & & & $\$$ & $4,320,000$ & $\$$ & $2,041,000$ & 8 & Shepherd, 2002 \\
\hline Metal silo, conical bottom w/ unloader & & & & & & & & & $\$$ & $1,276,000$ & 9 & Bridges, 2002 \\
\hline Concrete silo & & & & & & & $\$$ & $2,532,000$ & $\$$ & 855,000 & 10 & Kessler, 2002 \\
\hline Hopper, live-bottom, 9 mdrg chain conv & $\$$ & 42,300 & $\$$ & 42,300 & $\$$ & 35,850 & $\$$ & 35,850 & $\$$ & 26,153 & 11 & West, 2002 \\
\hline Conveyor, belted (33.5 m length) & $\$$ & 53,250 & $\$$ & 53,250 & $\$$ & 51,000 & $\$$ & 51,000 & $\$$ & 51,000 & 12 & West, 2002 \\
\hline Metal bldg w/ concrete pad, 1-side open & & & & & & & $\$$ & 244,000 & $\$$ & 62,000 & 13 & Archer, 2002 \\
\hline Open pile w/ concrete pad, sf & $\$$ & 5,958 & $\$$ & 5,958 & $\$$ & 121,124 & $\$$ & 41,719 & $\$$ & 28,338 & 14 & Thornton, 2002 \\
\hline Front end loader, rubber tired, w/ 9 m3 bucket & $\$$ & 250,000 & $\$$ & 250,000 & $\$$ & 250,000 & $\$$ & 250,000 & & & & Brammer, 2002 \\
\hline Magnet, bar & $\$$ & 7,600 & $\$$ & 4,800 & $\$$ & 4,800 & $\$$ & 4,800 & $\$$ & 3,975 & 15 & Gralnick, 2002 \\
\hline Magnet, self-cleaning bar & $\$$ & 17,100 & $\$$ & 11,950 & $\$$ & 8,400 & $\$$ & 7,800 & $\$$ & 7,800 & 16 & Gralnick, 2002 \\
\hline Magnet, pulley head & & & $\$$ & 5,995 & $\$$ & 4,685 & $\$$ & 2,645 & $\$$ & 2,645 & 17 & Gralnick, 2002 \\
\hline Non-ferrous metal detector & $\$$ & 9,965 & $\$$ & 9,965 & $\$$ & 6,475 & $\$$ & 6,475 & $\$$ & 6,475 & & Gralnick, 2002 \\
\hline Dryer, rotary & $\$$ & $3,300,200$ & $\$$ & $1,362,200$ & $\$$ & 887,200 & $\$$ & 521,000 & $\$$ & 250,000 & 18 & Ekberg, 2002 \\
\hline
\end{tabular}

\section{FN = FOOTNOTES}

1-Average price of several used trucks for sale. About $95 \%$ of small dump trucks have $12 \mathrm{~m} 3$ beds.

$2-13.7 \mathrm{~m}$ length, walking floor, self-unloading trailer van.

$3-13.7 m$ length.

4-Price is for two whole truck dumpers with hoppers at $\$ 302,000$ each, installed but concrete not included.

5-Installed costs.

6-See Table 7, screen support infrastructure included in price for hammermill (hog), installed

7-See Table 7, hammermills are sized to handle $30 \%$ of total flow and include $\$ 13,500$ for hog and screen support infrastructure. Price includes installation

8-See Fig 15 for picture of enclosed metal storage bin with traversing auger unloader.

9-Price is for four 9m dia $\times 12 \mathrm{~m}$ high metal silos (850 m3 each) at $\$ 319,000$ apiece, installed.

10 -With unloaders; $1 \mathrm{MW}=14.6 \mathrm{~m}$ dia. $\times 27.1 \mathrm{~m}$ high bolted steel silo installed on customer's foundation, $5 \mathrm{MW}=30.5 \mathrm{~m}$ dia. $\times 32.3 \mathrm{~m}$ high concrete dome, installed.

11-See Table 7 for details, used for feeding material into a scalping screen-hog processing system, installed

12-See Table 7 for details, used for moving material to storage, installed

13-Installed costs, bldg dimensions, $1 \mathrm{MW}=23.8 \mathrm{~m} \times 28.3 \mathrm{~m} \times 10.4 \mathrm{~m} \mathrm{~h}, 5 \mathrm{MW}=30.5 \mathrm{~m} \times 91 \mathrm{~m} \times 9 \mathrm{~m} \mathrm{~h}$, both with $6 \mathrm{~m}$ interior walls on the 3 closed sides.

14-At $10 \mathrm{MW}$ and above an earthen pad could be used with two $7.5 \mathrm{~m} \times 7.5 \mathrm{~m}$ concrete pads at feed hopper and truck dumper.

Cost each pad $=\$ 2,979$.

15-Cost increase is not linear due to matching requirements with standard models.

16 -Includes $\$ 1,000$ for mounting frame.

17 -Head pulley magnets not effective at 50MW.

18-See dryer cost breakdown on Table 8 and what is included in cost, does not include installation. 
Table 7 provides more detail on feed hoppers, scalping screens, hogs, and conveyor equipment costs, and includes information on motor sizes for operating costs.

Table 7. Cost Estimates for Conveyors and Hoppers (conveyor length dimensions are pulley to pulley and are installed costs)

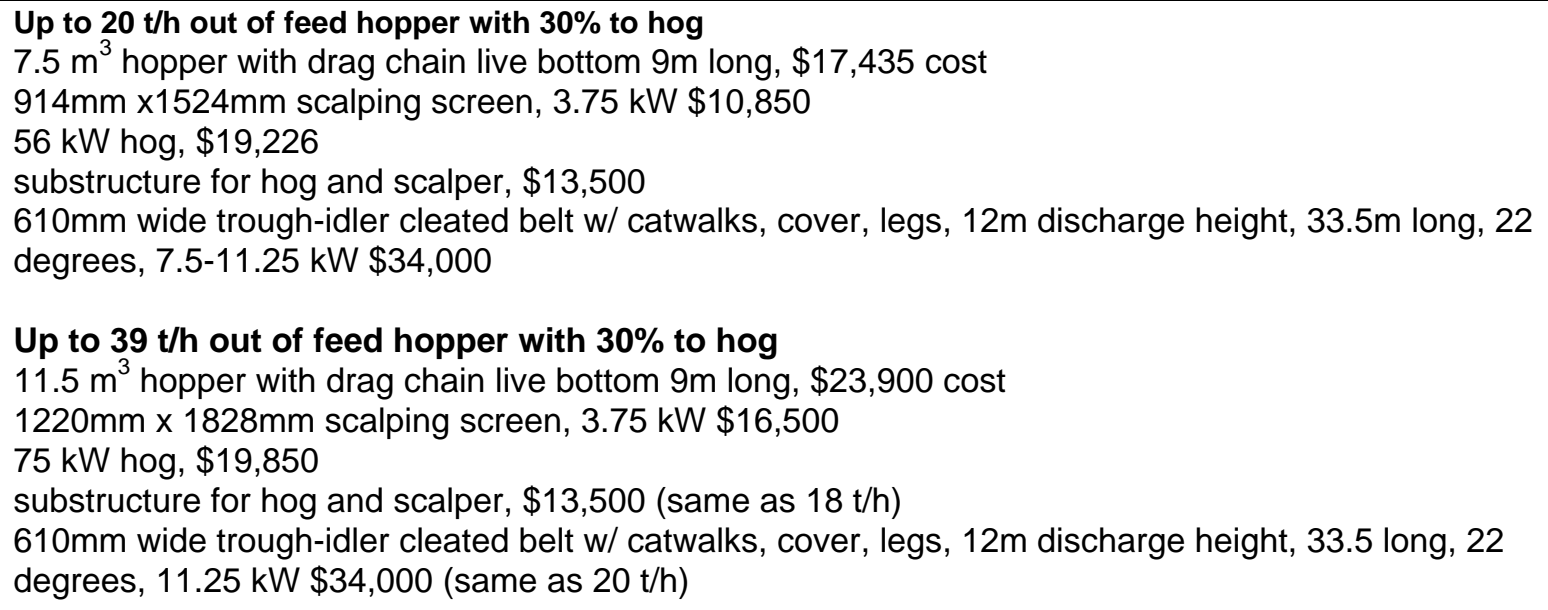

For trough-idler cleated belt conveyor up to lengths of $18-21 \mathrm{~m}$, the cost is essentially the same. Beyond $18-21 \mathrm{~m}$, add $\$ 328$ per meter of length.

To add Radial Stacker loader, use above figures except replace the $914 \mathrm{~mm}$ wide trough-idler cleated belt with the following:

$9 \mathrm{~m} \times 914 \mathrm{~mm}$ wide trough idler cleated belt conveyor beneath hog and scalper to convey to center pivot conveyor, $5.6 \mathrm{~kW}, \$ 11,300$.

$15 \mathrm{~m} \times 762 \mathrm{~mm}$ wide (pulley to pulley) trough idler cleated belt conveyor with center pivot, 175 degrees of rotation, $7.6 \mathrm{~m}$ high, 20 -degree incline, $7.5 \mathrm{~kW}$ motor, $\$ 24,780$.

Costs shown are equipment only costs. Installation costs, estimated at one-half the capital cost, are included in Table 6.

Source: West, 2002.

Table 8 provides estimated installed costs for rotary drum dryers. Model numbers indicate dryer characteristics. For example, using dryer model R1 60-30 at the $1 \mathrm{MW}$ system size, R1 indicates it is a single-pass system, 60 indicates the drum diameter is $1525 \mathrm{~mm}$ (60 inches), and 30 indicates the drum length is $9 \mathrm{~m}$ (30 feet). Table 9 gives energy requirements for rotary drum dryers. 
Table 8. Installed Costs for Rotary Drum Dryers Capable of Drying From 50 to $12 \%$ Moisture Content

\begin{tabular}{|c|c|c|c|c|c|c|c|c|c|c|c|}
\hline MW & Model Number & $\begin{array}{c}\# \\
\text { needed }\end{array}$ & & $\begin{array}{l}\text { Cost 1st } \\
\text { dryer }\end{array}$ & $\begin{array}{c}\text { Cost } \\
\text { additional }\end{array}$ & & $\begin{array}{l}\text { Total eqt } \\
\text { cost }\end{array}$ & & $\begin{array}{l}\text { tallation } \\
\text { costs }\end{array}$ & & $\begin{array}{l}\text { Total } \\
\text { nstalled } \\
\text { Costs }\end{array}$ \\
\hline$\overline{1}$ & R1 60-30 & 1 & $\$$ & 210,000 & NA & $\$$ & 210,000 & $\$$ & 39,000 & $\$$ & 249,000 \\
\hline 5 & R1 144-40 & 1 & $\$$ & 450,000 & NA & $\$$ & 450,000 & $\$$ & 71,000 & $\$$ & 521,000 \\
\hline 10 & R1 144-40 & 2 & $\$$ & 450,000 & less $10 \%$ & $\$$ & 855,000 & $\$$ & 142,000 & $\$$ & 997,000 \\
\hline 20 & R3 144-44 & 2 & $\$$ & 700,000 & less $10 \%$ & $\$$ & $1,330,000$ & $\$$ & 142,000 & $\$$ & $1,472,000$ \\
\hline 50 & R3 144-44 & 5 & $\$$ & 700,000 & less $10 \%$ & $\$$ & $1,330,000$ & $\$$ & 355,000 & $\$$ & $1,685,000$ \\
\hline
\end{tabular}

Source: Ekberg, 2002.

Table 9. Energy Requirements for Rotary Drum Dryers

\begin{tabular}{|c|l|l|l|}
\hline MWe & \multicolumn{1}{|c|}{ Model Number } & \multicolumn{1}{|c|}{ Electricity } & \multicolumn{1}{|c|}{ NG usage } \\
\hline 1 & R1 60-30 & Drive 3.725 KW, fan 19 $\mathrm{KW}_{\mathrm{e}}$ & $0.9 \mathrm{MW}_{\mathrm{t}}$ \\
\hline 5 & $\mathrm{R} 1144-40$ & $30 \mathrm{KW}_{\mathrm{e}}$ drive, fan $52 \mathrm{KW}_{\mathrm{e}}$ & $2.6 \mathrm{MW}_{\mathrm{t}}$ \\
\hline 10 & 2 dryers X R1 144-40 & $30 \mathrm{KW}_{\mathrm{e}}$ drive, fan $52 \mathrm{KW}_{\mathrm{e}}$ & $2.6 \mathrm{MW}_{\mathrm{t}}$ per dryer \\
\hline 20 & 2 dryers X R3 144-44 & $30 \mathrm{KW}_{\mathrm{e}}$ drive, fan 150 KW & $7 \mathrm{MW}_{\mathrm{e}}$ per dryer \\
\hline 50 & 5 dryers X R3 144-44 & $30 \mathrm{KW}_{\mathrm{e}}$ drive, fan 150 KW & $7 \mathrm{MW}_{\mathrm{t}}$ per dryer \\
\hline
\end{tabular}

Source: Ekberg, 2002.

Maintenance for rotary drum dryers involves the usual lubrication of bearings and the replacement of the metal rim around the circumference of the drum (the "tire") and the metal wheels on the dryer base that support the drum (trunnions). These replacements occur about once every five years and cost from $\$ 10,000$ to $\$ 20,000$, depending on system size. Additional expense may be incurred to repair internal flighting, if the flighting has been damaged by rocks or excessively heavy materials (Eckberg, 2002). 


\section{RECOMMENDATIONS FOR DECREASING ON-SITE CAPITAL AND O\&M COSTS ASSOCIATED WITH HANDLING}

\section{Limit onsite processing and handling}

The easiest way to reduce onsite costs is to require all fuel to be delivered already processed to the power plant's specifications, especially particle size, moisture content, and freedom from foreign materials. However, this will increase the cost of the fuel. In reality, depending on the initial wood characteristics at its source, and the final fuel characteristics required by the conversion device, all processing steps must be performed at some point between the wood supply and the conversion device. The power plant must then make a decision as to whether it is more cost effective to purchase fuel to specification or to process the fuel onsite. The basis for this decision depends on many factors in addition to cost, including confidence in the wood suppliers to deliver wood to specification, the hassle of processing wood onsite, the onsite availability of physical space for wood processing equipment, the availability of labor at the power plant for processing wood, and other factors.

There is also a trade-off between processing equipment capital and operating costs, including maintenance costs (especially labor). An additional trade-off concerns supply security. Having numerous suppliers provides more supply security than a few suppliers; however, it is easier to require a few suppliers to install additional wood processing equipment so they can supply wood to specification than to require many suppliers to install processing equipment. Minimizing onsite wood storage can also reduce processing costs; however, it can increase risk depending on fuel supply security.

Whether the power plant can require preprocessing will depend on the wood waste supply-demand situation in the power plant's fuel procurement region, including the power plant's own fuel needs. It will also depend on the commitment of the power plant to obtain fuel from specific sources so that these sources know they can repay their investment. Another factor is if wood waste generators are paying for wood waste disposal and, if so, the cost for disposal.

Regardless of whether fuel is purchased pre-processed or processed onsite, there are still minimal handling requirements at the power plant. These minimal operations include truck weighing, truck unloading, transfer of wood to storage, wood storage, and transfer of wood to the conversion device.

\section{Improper design}

Over-sizing equipment and storage systems can also create additional expense, as can failure to use lowest life cycle cost equipment and wood storage systems. Failure to use scalping screens before hogs to limit the amount of wood processed through the hog can lead to excessive energy use and wear on the hog. Equipment needs to be installed so as to minimize the need for (and expense for) support structures and to allow good access for routine maintenance.

\section{Use of fuel-flexible systems}

Choosing conversion systems to handle a wide range of feedstock physical characteristics can minimize the need for processing. 
Designing and scheduling to use equipment continuously (24 hours per day, 7 days per week) can reduce equipment sizes needed and spread operating costs over a larger base.

\section{Bio-oil systems}

Another option for decreasing costs is to convert the wood to bio-oil at an off-site facility or facilities. This has the advantage of removing alkali metals in the fuel, decreasing transportation costs, and simplifying storing and handling. Upon arrival at the biopower plant site, the bio-oil could be pumped into tanks until needed. No scales would be needed, as the bio-oil would be metered as it was pumped into storage. 


\section{REFERENCES}

Allen, J. Fred, 2001, State Forester, Georgia Forestry Commission, Macon, Georgia, personal communication.

Archer, Ricky, 2002, Oakland Metal Buildings, Inc., Florence, Alabama, personal communication.

Badger, P.C., J.L. Walsh, K.M. Morkin, J. Veitch, 1987, "Status of Industrial Wood-Fueled Systems," ASAE Paper No. 87-6008, American Society of Agricultural Engineers, St. Joseph, Michigan.

Brammer, Ed, 2002, personal communication, Asia Energy Ltd, Martinsville, Virginia.

Bridges, Gayle, 2002, Wellons, Inc., Hot Springs, Arkansas, personal communication.

Bromley, W.S., 1976, Pulpwood Production, Interstate Printers \& Publishers, Inc., Danville, Illinois.

Bundalli, Nazmir, 1998, Kamengo Technology, Inc., Richmond, British Columbia, company literature and personal communication.

Donovan, C.T. \& Associates, 1994, A Sourcebook on Wood Waste Recovery and Recycling in the Southeast, U.S. Department of Energy Southeastern Regional Biomass Energy Program, Tennessee Valley Authority, Muscle Shoals, Alabama.

Easterly, James L. and Michael Z. Lowenstein, 1986, Cogeneration from Biofuels: A Technical Guidebook, U.S. Department of Energy Southeastern Regional Biomass Energy Program, Tennessee Valley Authority, Muscle Shoals, Alabama (publication No. TV-67207A).

Ekberg, Hal, 2002, Aeroglide Corporation, Raleigh, North Carolina, personal communication.

EPA, 1999, Biosolids Generation, Use, and Disposal in the United States, US Environmental Protection Agency, publication EPA530-R-99-009.

Farley, John, 2002, Peerless Corporation, Paragould, Arkansas, personal communication.

FBT, Inc., 1994, Fluidized Bed Combustion and Gasification: A Guide for Biomass Waste

Generators, U.S. Department of Energy Southeastern Regional Biomass Energy Program, Tennessee Valley Authority, Muscle Shoals, Alabama.

Georgia Tech (Georgia Institute of Technology), 1984, The Industrial Wood Energy Handbook, Van Nostrand Reinhold Company, New York, New York .

Goldstein, Nora, 2001, "Dust, Noise, Projectiles: Protective Practices at Grinding, Screening Operations," Biocycle Magazine, October, pp 49-53.

Gralnick, Marshall, 2002, MasterMag, Global Equipment Marketing, Inc., Boca Raton, Florida, personal communication. 
GLRBEP, 1986, Industrial/Commercial Wood Energy Conversion: A Guide to Wood Burning, Fuel Storage \& Handling Systems, published by Great Lakes Regional Biomass Energy Program, Council of Great Lakes Governors, Chicago, Illinois (DOE Contract DE-FG05-830R21390).

Irving, John, 2002, Burlington Electric Department, Burlington, Vermont, personal communication.

Jiles, John, 2002, Peerless Corporation, Milledgeville, Georgia, personal communication.

Kessler, Mark, 2002, Laidig Industrial Systems, Huntersville, North Carolina, personal communication.

Makansi, Jason, 1980, "Power from Wood: A Special Report," Power Magazine, February. Milota, Michael R., 2000, "Emissions from Wood Drying: The Science and the Issues," Forest Products Journal, Vol. 50, No. 6. pp 10-20.

Phillips, Jim, 2002, Alabama Department of Environmental Management, Water Division, Industrial Section, Montgomery, Alabama, personal communication.

Skov, Niels A. and Mark L. Papworth, 1974, The Pegasus Unit, Pegasus Publishers, Inc., Olympia, Washington.

Schmidt, Katherine \& Associates, 1991, Biomass Design Manual Industrial Size Systems, U.S. Department of Energy Southeastern Regional Biomass Energy Program, Tennessee Valley Authority, Muscle Shoals, Alabama.

Shepherd, Terry, 2002, Clarke's International, Inc., Eugene, Oregon, personal communication.

Thomas, Dani, 2002, BoMax, Inc., Phoenix, Arizona, personal communication and website, www.bomax.com.

Thornton, Ben, 2002, Auburn University, Building Sciences Department, personal communication.

Trulove, Hubert, 2002, Tractor Supply, Inc., Leighton, Alabama, personal communication.

West, Mike, 2002, Precision Husky Corporation, Leeds, Alabama, personal communication. 
ORNL/TM-2002/199

\section{INTERNAL DISTRIBUTION}

$\begin{aligned} \text { 1-20. } & \text { J. Cushman } \\ 21 . & \text { M. Downing } \\ 22 . & \text { R. Graham } \\ 23 . & \text { S. G. Hildebrand } \\ \text { 24. } & \text { L. Kszos } \\ \text { 25. } & \text { A. Leinonen } \\ 26 . & \text { E. Peelle } \\ 27 . & \text { R. Perlack }\end{aligned}$

\author{
28. S. Sokhansanj \\ 29. V. Tolbert \\ 30. A. Turhollow \\ 31. G. Tuskan \\ 32. M. Walsh \\ 33. L. Wright \\ 34-36. ESD Library \\ 37. ORNL Central Research Library \\ 38. ORNL Laboratory Records-RC
}

\section{EXTERNAL DISTRIBUTION}

39-48. Phillip Badger, General Bioenergy, Inc., 3115 Northington Court, Florence, AL 35631

49. Richard Bain, National Renewable Energy Laboratory, 1617 Cole Blvd., Golden, CO 80401

50. John Ferrell, U.S. Department of Energy, Office of Fuels Development, EE-31, Room 6A-116, Forrestal Building, 1000 Independence Avenue, SW, Washington, DC 20585

51. Paul Grabowski, U.S. Department of Energy, Biopower Technologies, EE-13, Forrestal Building, 1000 Independence Avenue, SW, Washington, DC 20585

52. Douglas Kaempf, U.S. Department of Energy, Bioenergy Initiative, EE-24, Room 5F-035, Forrestal Building, 1000 Independence Avenue, SW, Washington, DC 20585

53. Jim McMillan, National Renewable Energy Laboratory, 1617 Cole Blvd., MS 3511, Golden, CO 80401

54. Tien Nguyen, U.S. Department of Energy, Office of Fuels Development, EE-31, Room 6B-025, Forrestal Building, 1000 Independence Avenue, SW, Washington, DC 20585-0121

55. Mark Paster, U.S. Department of Energy, Office of Industrial Technologies, EE-22, Forrestal Building, 1000 Independence Avenue, SW, Washington, DC 20585

56. Donald Richardson, U.S. Department of Energy, Office of Biopower \& Hydropower, EE-13, Room 5H-047, Forrestal Building, 1000 Independence Avenue, SW, Washington, DC 20585

57. Cindy Riley, National Renewable Energy Laboratory, 1617 Cole Blvd., Golden, CO 80401

58. Sarah Sprague, U.S. Department of Energy, Office of Fuels Development, EE-31, Forrestal Building, 1000 Independence Avenue, SW, Washington, DC 20585 